Cahiers Charlevoix

Études franco-ontariennes
Cahiers Charlevoix Études franco-ontariennes

or Crevenerix of

\title{
Régis Roy (1864-1944) ou la mise en vers de facéties du terroir
}

\section{Jean-Pierre Pichette}

Volume 12, 2018

URI : https://id.erudit.org/iderudit/1048920ar

DOI : https://doi.org/10.7202/1048920ar

Aller au sommaire du numéro

Éditeur(s)

Société Charlevoix

Presses de l’Université d'Ottawa

ISSN

1203-4371 (imprimé)

2371-6878 (numérique)

Découvrir la revue

Citer cet article

Pichette, J.-P. (2018). Régis Roy (1864-1944) ou la mise en vers de facéties du terroir. Cahiers Charlevoix, 12, 217-274. https://doi.org/10.7202/1048920ar

\section{Résumé de l'article}

Pour sa part, Jean-Pierre Pichette verse un nouveau chapitre au dossier de la transposition des récits oraux dans des oeuvres littéraires. À l'analyse des écrits destinés à la jeunesse de l'écrivaine Marie-Rose Turcot (Cahiers Charlevoix 3) et de l'ethnologue Marius Barbeau (Cahiers Charlevoix 4), il ajoute l'examen des " petits contes drolatiques " qu'un autre écrivain d'Ottawa, Régis Roy (1864-1944), a publiés entre 1906 et 1928. Cet auteur affirme avoir tiré " du terroir ", donc lui-même entendu, les 132 récits brefs et amusants qu'il a mis en vers dans ses trois recueils. La rusticité de sa poésie découle nettement de la source populaire de son inspiration. Par la comparaison d'un échantillonnage de "petits monologues comiques en prose rimée " avec des variantes relevées dans la tradition orale canadienne-française, cette étude entend démontrer que les ingrédients de son humour sont vraiment les " bons mots du terroir ». En choisissant de mettre en vers des contes facétieux - fabliaux véritables fondés sur des sottises, ruses, quiproquos et calembours - Régis Roy s'est taillé une place originale dans le courant terroiriste de son temps.
Ce document est protégé par la loi sur le droit d'auteur. L'utilisation des services d’Érudit (y compris la reproduction) est assujettie à sa politique d'utilisation que vous pouvez consulter en ligne.

https://apropos.erudit.org/fr/usagers/politique-dutilisation/ 


\title{
Régis Roy (1864-1944) ou la mise en vers de facéties du terroir
}

\author{
JeAn-Pierre Pichette \\ Chaire de recherche en oralité \\ des francophonies minoritaires d'Amérique (COFRAM) \\ Université Sainte-Anne, Pointe-de-1’Église
}




\section{SOMMAIRE}

$\begin{array}{ll}\text { INTRODUCTION } & 219\end{array}$

A. L'auteur 219

B. Trois recueils de contes joyeux 221

I - Des CONTES DU TERROIR 224

A. «Des contes gais venus de la campagne » 226

B. Les personnages 226

C. Des anecdotes amusantes 227

II - EXAMEN COMPARATIF D'UN CHOIX DE CONTES 230

A. Les contes 230

1. La Noël 230

2. Les deux chats 236

3. Pas tous à la fois 242

4. La vache perdue de Gros-Jean 247

5. "Et bonae voluntatis» 252

6. À telle enseigne 255

7. Tout son temps 259

8. Octave de Noël 264

B. La veine populaire avérée 267

$\begin{array}{ll}\text { CONCLUSION } & 269\end{array}$

A. Un poète oublié ? 269

B. Dans un entre-deux littéraire 271

C. L'exemple des fabliaux 272 


\section{Régis Roy (1864-1944) ou la mise en vers de facéties du terroir}

\begin{abstract}
En tant que les fabliaux sont, pour la plupart, des contes traditionnels, qui vivaient avant le XIII siècle et qui vivent encore aujourd'hui, ils font partie du trésor des littératures populaires; ils avoisinent les contes merveilleux et les fables, et comme tels intéressent les folkloristes; car la question de leur origine et de leur transmission se pose pareillement pour eux et pour les autres groupes de contes populaires.
\end{abstract}

JOSEPH BÉDIER ${ }^{1}$

\section{INTRODUCTION}

\section{A. L'auteur}

Régis Roy (1864-1944), écrivain d'Ottawa, est aujourd'hui connu d'un très petit nombre de chercheurs dans le champ de la littérature franco-ontarienne. Ce fonctionnaire fédéral, qui fit carrière au ministère de l'Agriculture (1882-1884) puis à celui de la Marine (1884-1939) et que les dictionnaires présentent comme « dramaturge, romancier, conteur et historien ${ }^{2} »$ ou « journaliste et littérateur, héraldiste et historien ${ }^{3} \gg$ serait le premier écrivain de langue française né en Ontario ${ }^{4}$. Son œuvre compte une vingtaine

1. Joseph Bédier, Les Fabliaux. Études de littérature populaire et d'histoire littéraire du moyen âge, Sixième édition, Paris, Champion, et Genève, Slatkine, 1982 [2 édition, Paris, Émile Bouillon, 1895], p. 2.

2. Réginald Hamel, John Hare et Paul Wyczynski, Dictionnaire des auteurs de langue française en Amérique du Nord [désormais DALFAN], Montréal, Fides, 1989, p. 1199.

3. Maurice Lemire (dir.), Dictionnaire des auvres littéraires du Québec, tome I - Des origines à 1900, Montréal, Fides, 1978, p. 140. Voir aussi Charles Dufresne et al., Dictionnaire de l'Amérique française - Francophonie nord-américaine hors Québec, Ottawa, Presses de l'Université d'Ottawa, 1988, p. 321 : « fonctionnaire et écrivain »; Gaétan Gervais et Jean-Pierre Pichette (dir.), Dictionnaire des écrits de l'Ontario français 1613-1993 [désormais DÉOF], Ottawa, Presses de l'Université d'Ottawa, 2010, p. 1001 : « fonctionnaire, journaliste, écrivain et historien ».

4. Jacques Langlais, " Bio-bibliographie analytique de Régis Roy », Préface 
d'ouvrages autonomes qui se déclinent pour une première moitié en comédies en un acte, et pour l'autre en romans historiques, études d'histoire et d'héraldique, et recueils de contes, le tout paru entre 1896 et $1931^{5}$. Autodidacte, amateur d'histoire et protégé de Benjamin Sulte (1841-1923), Régis Roy collabore dès 1890 à une quinzaine de périodiques, dont Le Monde illustré, Le Canard, Le Passe-Temps et le Pays laurentien pour ses œuvres de création, nouvelles ou récits en vers, et, à compter de 1895, le Bulletin des recherches historiques pour ses très nombreuses prospections du côté de l'histoire et de l'héraldique. Il publie ainsi, tantôt sous son nom propre ou sous divers pseudonymes - N. Durand, Roland de Roye, Willy de Grécourt, Robert de Longueuil -, plus de 400 articles sans compter ceux qu'il rédige pour le quotidien Le Droit ${ }^{6}$. Ses farces en un acte ont été jouées fréquemment et ses ouvrages ont généralement reçu bon accueil. Le jugement qu'on a porté sur ses écrits paraît d'ailleurs juste : « Sans réaliser des œuvres de grande qualité, Régis Roy demeure néanmoins un des plus prolifiques auteurs franco-ontariens de son époque. ${ }^{7}$ ')

Au début du nouveau millénaire, son œuvre a connu un regain d'intérêt. Les professeurs Mariel O'Neill-Karch et Pierre Karch en ont tiré deux recueils parus aux Éditions David dans la collection « Voix retrouvées »: d'abord, Choix de nouvelles et de contes, une édition de dix-huit récits sélectionnés parmi la trentaine que l'auteur a publiés ${ }^{8}$, puis Théâtre comique de Régis Roy, l'intégrale

de Marie-Claire Daveluy, Montréal, Université de Montréal, École de bibliothécaires, 1947, IV-108 p. ; voir sa biographie, p. 1-16.

5. Ils ont tous fait l'objet d'une inscription dans le DÉOF, op. cit.

6. Jacques Langlais, « Bio-bibliographie analytique de Régis Roy», op. cit. Ce mémoire compile 359 entrées parues dans quinze revues et deux journaux ; l'auteur note que « Régis Roy a écrit beaucoup d'articles dans [le] quotidien [Le Droit, mais il n'a] pas pu en faire le relevé » (p. 75) ; à ceux-là, s'ajoutent 33 textes courts repérés lors du dépouillement incomplet de l'hebdomadaire Le Canard. On recense ses articles principalement dans Le Monde illustré (41 art.), Le Passe-Temps (35 art.), le Pays laurentien (14 art.) et le Bulletin des recherches historiques (238 art.).

7. DALFAN, op. cit., p. 1199.

8. Régis Roy (1864-1944), Choix de nouvelles et de contes, Édition préparée par Mariel O’Neill-Karch et Pierre Karch, Ottawa, Éditions David, « Voix retrouvées » 2, 2001, 282 p. 
de son œuvre dramatique essentiellement composée de farces et de comédies ${ }^{9}$.

\section{B. Trois recueils de contes joyeux}

Ce sont ses écrits d'un autre genre qui nous intéressent ici. Entre 1906 et 1928, Roy a édité trois recueils de récits facétieux ; pour la plupart diffusés antérieurement dans des périodiques montréalais, ces contes avaient la particularité d'être rimés. La collection qu'il a rassemblée de la sorte compose un corpus de cent trente-deux pièces.

C'est sous le pseudonyme de Willy de Grécourt, qui s'affiche comme « collaborateur au Canard», que l'auteur publie à Ottawa, en 1906, un premier titre : Les Joyeux Petits Contes canadiens ${ }^{10}$. Le recueil reprend " une série de petits contes drôlatiques [sic] [c]anadiens publiés de temps à autre, principalement dans le Canard, de Montréal ${ }^{11}$ ». Récits brefs en effet, puisque les deux tiers des cinquante-six histoires que l'auteur a arrangées occupent tout juste une page ; les plus courtes n'ont que quatre vers, d'autres tiennent en deux ou trois pages, une seule en compte cinq. Leur parution dans Le Canard (1877-1907), un hebdomadaire humoristique fondé à Montréal par Hector Berthelot, est avérée : Willy de Grécourt avait signé trente-trois d'entre elles entre le 26 août 1899 et le 17 octobre $1903^{12}$. Selon l'auteur, cette brochure originale, sans prétention littéraire, poursuivait une fin bien modeste : « nous avons voulu faire œuvre divertissante, rien de plus, et si

9. Théâtre comique de Régis Roy (1864-1944), Édition préparée par Mariel O’Neill-Karch et Pierre Karch, Ottawa, Éditions David, « Voix retrouvées » 8, 2006, $355 \mathrm{p}$.

10. Willy de Grécourt [pseudonyme de Régis Roy], Les Joyeux Petits Contes canadiens, Ottawa, The Mortimer Co. Limited, 1906, 83 p.

11. Ibid., «Préface », p. [3]. Un récit, «Le Perroquet qui parle », a paru dans Le Passe-Temps, $1^{\text {er }}$ mars 1902, p. 19, sous le pseudonyme de Roland de Roye.

12. Ces récits sont répartis inégalement selon les années, le plus grand nombre paraissant en 1902 (8) et en 1903 (23), un récit seulement pour chacune des années 1899 (1) et 1901 (1), mais aucun pour 1900. Le seul petit conte en vers publié sous le pseudonyme de Willy de Grécourt en 1899 n'a pas été retenu dans la compilation d'Aurélien Boivin, Le Conte littéraire québécois au XIX siècle. Essai de bibliographie critique et analytique, Montréal, Fides,1975, XXXVIII-385 p. 
notre lecteur la goûte ainsi, il sera indulgent, certainement, pour cette versification. » La rusticité de sa poésie, pour laquelle Roy réclame ainsi l'indulgence de son lectorat, découle apparemment de l'origine populaire de son inspiration, car, comme l'affirme Roy dans sa préface, d'un « certain nombre de contes amusants que nous avons entendus, nous n'avons choisi que ceux qui étaient du terroir ${ }^{13} \gg$. Bon nombre de ces histoires, mettant en scène la vie quotidienne des gens ordinaires, reposent essentiellement sur des quiproquos, des calembours, des mots d'enfant et autres jeux de mots, dont quelques-uns sont à double sens.

Les deux volumes suivants paraîtront sous le nom véritable de leur auteur. Dans la veine du recueil paru dix ans plus tôt à Ottawa, Régis Roy exploite, dans L'Épluchette ${ }^{14}$, le même filon populaire, ainsi qu'il le laisse entendre dans un avant-propos en vers : « Depuis longtemps j'ai souvent entendu / Des contes gais venus de la campagne ». Mais, cette fois, il confesse que « chez les uns trop de sel accompagne / L'esprit rural » ou « chez d'autres, c'est rendu / Avec des mots qui sentent trop la terre ». Il en conclut : «Il fallait donc, pour vous, ami lecteur, / [...] une épluchette faire ${ }^{15} »$. Cette image de l'« épluchette », s'il faut l'entendre au sens de la fête d'automne, au cours de laquelle on épluche les épis de blé d'Inde ou de maïs pour les faire cuire avant de les manger en famille et entre amis, comporte aussi l'idée de décortiquer les récits afin de les rendre présentables au lecteur. Par exemple, la finale « épluchée » d'un des neufs récits, qu'il a extraits du recueil de 1906, révèle le sens second de cette expression; la conclusion « Mais, ains 'soit-il, c'est-i' d'la crotte? » s'y voit adoucie en « Mais ains' soit-il, quoi qu'vous en faites ? ${ }^{16} »$

13. Willy de Grécourt, op. cit., «Préface », p. [3].

14. Régis Roy, L'Épluchette. Contes joyeux des champs, Montréal, Gérard Malchelosse, éditeur, 1916, 137 p.

15. « L'Épluchette », dans L'Épluchette, op. cit., p. 7.

16. «Trois ou quatre », op. cit., p. 32 ; Joyeux Petits Contes canadiens, p. 42. Il s'agit de la protestation d'un père qui défend son fils renvoyé du catéchisme pour avoir répondu qu'il y a quatre personnes en Dieu et non trois seulement, « Père, Fils et Saint-Esprit »; il croit qu'Ainsi-soit-il est le nom de la quatrième. 
L'ouvrage renferme en tout soixante et onze poèmes assez courts, qui ne dépassent pas pour la grande majorité une ou deux pages, et qui composent la collection la plus imposante qu'il publiera dans ce style. Pour assurer l'unité de son livre, l'auteur a créé les types de Gros-Jean Deschamps et des membres de sa famille, qui constituent les héros de presque tous ces « contes joyeux des champs », multipliant ainsi les anecdotes, les naïvetés, les bons mots, les ruses et même les sottises.

Douze ans plus tard, fort de ses succès précédents, Régis Roy donne en 1928 un troisième et ultime ouvrage dans ce genre léger : Joyeux Propos de Gros-Jean ${ }^{17}$. Il s'en explique ainsi :

Il est bon de rire de temps à autre. L'esprit français est suprême dans le domaine des historiettes gaies, amusantes, et nous trouvons cette caractéristique partout chez nos bons Canadiens. Nous avons publié déjà une série de ces petits contes, bons mots du terroir, sous le titre de L'Épluchette, dont l'édition s'est enlevée en quelques semaines. Nous lançons cette nouvelle série dans l'espoir qu'elle recevra le même accueil que son aînée et qu'elle pourra également égayer, amuser nos lecteurs. ${ }^{18}$

En omettant, sans justification apparente, ses Joyeux Petits Contes canadiens, ce recueil publié en 1906 sous pseudonyme, il laisse entendre que L'Épluchette est sa première série de « bons mots du terroir ». Pourtant, ce deuxième ouvrage reprenait neuf récits de Willy de Grécourt et le troisième en exhumait maintenant douze autres, soit près de la moitié des « monologues » que comprenait ce nouveau florilège ; il est vrai que ces reprises sont publiées après révision, correction, adaptation ou complet remaniement. Ces vingt-six pièces portent à cent trente-deux le total de ces petits contes à rire d'inspiration folklorique que l'auteur a mis en vers ${ }^{19}$.

En dépit du titre, le personnage même de Gros-Jean, qui occupait toute la scène de L'Épluchette, n'est présent que dans

17. Régis Roy, Joyeux Propos de Gros-Jean. Petits monologues comiques en prose rimée, Illustrations de Albéric Bourgeois, Montréal, Les Cahiers populaires, $1928,105 \mathrm{p}$.

18. Régis Roy, «Préface », Joyeux Propos de Gros-Jean, op. cit., p. [8].

19. Il y a bien 132 contes différents, mais 153 versions en incluant les reprises. 
le tiers à peine de ces « petits monologues comiques en prose rimée ». Pourtant, les ingrédients de leur humour demeurent constants : anecdotes naïves faites de quiproquos, de jeux de mots et de doubles sens. Les douze illustrations pleine page d'Albéric Bourgeois agrémentent la lecture tout en aérant le texte.

\section{I - DES CONTES DU TERROIR}

Dans sa première compilation, Les Joyeux Petits Contes canadiens, Régis Roy déclarait n'avoir retenu, parmi les récits facétieux qu'il avait entendus, « que ceux qui étaient du terroir ». Par cet aveu, il souscrivait à une longue tradition littéraire, car, bien avant l'ère des folkloristes et des ethnologues, de nombreux auteurs, et non des moindres, ont transposé dans leurs créations les contes oraux de leur époque. Le Roman de Renart (XII ${ }^{\mathrm{e}}$-XIII ${ }^{\mathrm{e}}$ siècles), les fabliaux du Moyen-Âge (XIII ${ }^{\mathrm{e}}-\mathrm{XIV}^{\mathrm{e}} \mathrm{s}$.), la Farce de maître Pierre Pathelin $\left(\mathrm{XV}^{\mathrm{e}} \mathrm{s}\right.$.), l'œuvre entière de François Rabelais ( $\mathrm{XVI}^{\mathrm{e}} \mathrm{s}$.) et les contes de Charles Perrault (XVII ${ }^{\mathrm{e}} \mathrm{s}$.) en incarnent certes les plus illustres monuments du domaine français, comme il s'en trouve encore dans quelques autres langues et cultures : les contes des Mille et Une Nuits ( $\left.\mathrm{x}^{\mathrm{e}} \mathrm{s}.\right)$, de Boccace (XIV $\left.{ }^{\mathrm{e}} \mathrm{s}.\right)$, de Straparole (XVI $\left.{ }^{\mathrm{e}} \mathrm{s}.\right)$, de Basile (XVII ${ }^{\mathrm{e}} \mathrm{s}$.) et des frères Grimm ( $\mathrm{XIX}^{\mathrm{e}} \mathrm{s}$.) pour ne citer que les plus connus. Mais l'inclusion de la tradition orale dans des œuvres est beaucoup plus ancienne, comme en témoignent des écrits anonymes plusieurs fois millénaires. Paul Delarue, en présentant son Catalogue du conte populaire français, note cependant que « [...] ce n'est que par accident, par une chance exceptionnelle qu'un conte populaire dont la transmission se faisait par voie orale est passé parfois dans une œuvre écrite où nous le reconnaissons, malgré les déformations qu'il peut avoir subies. ${ }^{20}$ » Néanmoins, il avançait avec assurance qu' « [u]n grand nombre de ces contes, et particulièrement les contes merveilleux, se disaient déjà il y a des siècles et des siècles, parfois depuis des millénaires, parfois

20. Paul Delarue, Le Conte populaire français, catalogue raisonné des versions de France et des pays de langue française d'outre-mer [...], Tome premier, Paris, G.-P. Maisonneuve et Larose, [1957], p. 10. 
dans un insondable passé qui échappe à nos investigations. ${ }^{21}$ " À l'appui de son assertion, il citait en exemples le Grand Voleur de Paris (Atu 950) qui pille le trésor royal et dont Hérodote, au $\mathrm{V}^{\mathrm{e}}$ siècle avant Jésus-Christ, attribue l'histoire au roi Rhampsinite ; le conte du géant aveuglé par son prisonnier (ATU 1137) qu'Homère met en scène dans l'Odyssée, au $\mathrm{IX}^{\mathrm{e}}$ siècle av. J.-C., quand Ulysse crève l'œil du cyclope Polyphème ; et, plus ancien encore, le conte égyptien des Deux Frères, du XIII siècle av. J.-C., qui contient des "séquences de motifs 》 attestés dans toute 1'Europe ${ }^{22}$. La Bible elle-même, dans plusieurs textes de l'Ancien Testament (VIII ${ }^{\mathrm{e}}$-II ${ }^{\mathrm{e}}$ siècle av. J.-C.), comporte aussi des adaptations de contes populaires ${ }^{23}$.

Ce fut sans doute là l'un des vertiges des premiers chercheurs de terrain chaque fois qu'ils récoltaient dans la tradition orale, et très souvent de conteurs illettrés, des récits dont ils connaissaient une version littéraire. Et l'on s'est posé cette question : la tradition dérive-t-elle du livre ou le livre de la tradition ? Avec combien d'autres questions sur l'origine des contes, qui resteront pour longtemps encore insolubles; c'est que « [...] la réalité du conte est trop complexe pour que l'on puisse expliquer dès maintenant par une formule polyvalente ces questions d'origine qui sont précisément les plus difficiles à élucider et qui ne le seront peut-être que les dernières si elles le sont un jour. ${ }^{24}$ "

Dans le cas des contes en vers à l'étude, Régis Roy a facilité la tâche du chercheur en déclarant sans façon la nature populaire de sa « série de [...] petits contes, bons mots du terroir ». Ce faisant, il indiquait clairement dans quel sens l'influence avait opéré. Dès lors, pour éprouver la véracité de sa déclaration, il importe d'échantillonner des récits versifiés afin de les confronter à des

21. Ibid., p. 7.

22. Ibid., p. 8.

23. Par exemple, on reconnaît dans le Livre de Tobie le thème du Mort reconnaissant (AтU 506).

24. Paul Delarue, «Préface », dans Roger Pinon, Le Conte merveilleux comme sujet d'études, Liège, Centre d'éducation populaire et de culture, "Études régionales "Introductions au folklore" ", 1955, p. 4. 
versions parallèles tirées de la tradition orale du Canada français, c'est-à-dire du milieu le plus proche de celui qu'a connu l'auteur. C'est seulement par ce travail de comparaison qu'on parviendra à la démonstration de l'origine populaire probable de quelques-uns des fabliaux du répertoire de l'auteur d'Ottawa.

Mais d'abord, examinons-en le cadre.

\section{A. «Des contes gais venus de la campagne »}

Par le titrage de chacune de ses œuvres, Régis Roy annonce déjà le programme de sa trilogie en devenir. Rappelons-en les intitulés pour mémoire : Les Joyeux Petits Contes canadiens (1906), L'Épluchette. Contes joyeux des champs (1916) et Joyeux Propos de Gros-Jean. Petits monologues comiques en prose rimée (1928). Le genre ne fait pas de doute : ce sont bien des contes pour les deux premiers titres et des propos en forme de monologues pour le troisième. Il est clair aussi que ce sont des contes à rire, des histoires drôles, le qualificatif « joyeux » étant omniprésent ; l'auteur se propose clairement de divertir son lecteur comme l'explicite encore l'épithète « comiques » apposée aux « monologues ». Même sans les mentions « petits contes » du premier recueil et « petits monologues » du troisième, on en déduirait que ces histoires sont brèves, la brièveté étant caractéristique des histoires drôles. La dimension rurale de ces « contes gais venus de la campagne » colore surtout les deux dernières compilations par l'allusion à la coutume de l'épluchette, à l'origine des récits qui sont « des champs » ou au personnage de Gros-Jean ; et, d'après le premier livre, cette ruralité met en scène l'univers « canadien », c'est-à-dire canadien-français. Quant à la forme, seul le troisième titre précise que l'auteur a composé ses récits en "prose rimée ».

\section{B. Les personnages}

En prenant L'Épluchette à témoin, qui regroupe à lui seul plus de la moitié des contes du répertoire, le milieu populaire apparaît avec grande insistance. La vie se déroule essentiellement dans une paroisse rurale avec son église et son école, et ceux qui ont charge 
d'y fournir les services : les sédentaires, l'institutrice Lagacé, le notaire, le pharmacien, le dentiste, le photographe, le commis de café, le garçon de ferme, le maréchal-ferrant; et les étrangers de passage, le colporteur, le camelot, le commis voyageur JeanBaptiste Maugras et le mendiant. Gros-Jean Deschamps, qui est maire de la paroisse des Grands-Bois, dont il fut le bedeau, monopolise l'action avec sa famille : il est présent dans quarantehuit contes, soit les deux tiers du recueil, son épouse maman Deschamps, douze fois, deux de leurs fils, Michel, neuf fois, et Nicole, dit Joufflu, sept fois, et leur fille Simplice, huit fois. Les grands-parents Deschamps et l'aïeul Moïse y figurent à l'occasion avec quelques-uns des autres enfants du couple, qui sont onze ici et près de trente là, Gros-Jean s'étant remarié : les garçons Nicolas, Christophe, Pacôme, les jumeaux Toinon et Poléon, et Fanfan, et les filles Suzon et Nanette, Josette, Luce et Rose ; et les cousins de Gros-Jean, Jean-Baptiste et Saint-Laurent. Le curé du village, ou son vicaire, intervient dans seize récits, comme prédicateur ou confesseur; des voisins parfois, le père Lalonde, le père Ladéroute et Élise, la fille d'un voisin. Telle est la distribution paysanne dont Régis Roy raconte la chronique en épisodes.

\section{Des anecdotes amusantes}

Les trois recueils de Régis Roy proposent le même registre d'humour qui était coutumier aux lecteurs du Canard et de la rubrique des divertissements du Passe-Temps (1895-1949), revue culturelle à vocation musicale fondée par Joseph-Émilio-Sibert Bélair (1865-1933). Cependant, sa mise en forme poétique lui est particulière, d'autant qu'elle met à l'honneur des récits « du terroir » qui se disent ordinairement en prose. À n'en pas douter, l'inspiration populaire est claire, un grand nombre de ces textes ayant des parallèles dans la littérature orale.

Avant d'analyser plus spécialement quelques-unes de ces proses poétiques, voyons-en la teneur par les quelques exemples représentatifs résumés ci-dessous. Dans l'ensemble, ce sont les jeux de mots qui semblent fasciner 1'auteur. À côté des mots 
d'enfants bien innocents de « Parodie » :

Le dernier vers d'un chant pieux que chante une mère - « Dans ce moment, mon âme est toute en feu !»- est interprété par une enfant distraite : « Danse maman, mon oncle est tout en feu !» (1906, p. 35)

et des naïvetés d'adolescents, comme la strophe unique de « La Danse » :

Simplice interrogeait un prêtre :

- Je voudrais bien connaître

Si danser est un mal ?

- Oui, dit-il, si vous dansez mal! (1906, p. 8 ; 1916, p. 102), il se trouve aussi des calembours d'adultes, ce que montre « Diction »:

Une dame lit des vers. "La belle diction!", s'exclame un spectateur à son époux : « Ce n'est rien, sur mon âme! / Si vous connaissiez sa contradiction! » (1928, p. 69)

L'auteur rapporte aussi de courtes scènes de la vie courante dans lesquelles les bons mots se muent parfois en réparties cinglantes. C'est la réaction contrariée d'un fumeur de cigare dans « En attendant le train » :

Une voyageuse, incommodée par la fumée du mauvais cigare de Gros-Jean, le traite de polisson et lui dit qu'elle lui donnerait « Une bonne dose de poison / Si j'avais l'infortune / De vous avoir pour mari ! » Ce à quoi Gros-Jean rétorque, « fumant épais »: "Si j'étais votre homme [...] / Vite j'm'empoisonnerais ! » (1916, p. 79-80)

ou le cas de la fine riposte de Jeanneton dans «Contraste» :

«Un Narcisse faisait le frais, / Sûr de la beauté de ses traits »; il souhaitait unir sa destinée à une laideronne pour faire «Un contraste aussi grand et vaste / Que possible ». Jeanneton lui répondit : «Qu'elle soit ou laide ou jolie, / Pour contraster avec profit / Prenez une femme d'esprit !» (1916, p. 115).

Comme dans ses farces, Régis Roy est friand des quiproquos. L'équivoque de « Sa prestesse (sonnet) » relève de niveaux de langue différents : 
En descendant de voiture, le vêtement d'une dame reste accroché et montre ce qui ne devrait pas l'être... La dame se dégage vitement et dit à l'homme présent : " Vous avez vu, monsieur, n'est-ce pas, ma prestesse ? » L'homme lui répond : «Ben l'pardon, madame la princesse : / Nous aut' on appell' ça :... Non ; j'm'tais par politesse ! » (1906, p. 9)

Le malentendu décrit dans «Adam » est plus caricatural :

Pendant le sermon du curé « sur la création d'Adam et d'Ève », un habitant revient dans l'église tout juste au moment où Jéhovah, s'adressant au premier homme, conscient de sa désobéissance, dit : "Adam ! d'où viens-tu ? » L'habitant, qui se prénomme aussi Adam, répond, croyant que le prêtre s'adresse à lui : « J'viens d'voir à ma jument grise ! » (1928, p. 89-90)

Les échanges ambigus qui prêtent indirectement flanc à des méprises surgissent dans des situations les plus ordinaires. Par exemple, au moment de la toilette d'un enfant dans « Le Possible de Jovite $»$ :

Un gamin qui a pris son bain un peu vite, disant qu'il s'est lavé " aussi haut que possible » et « aussi bas que possible », est rabroué par sa mère : « Marche te laver le possible ! (1906, p. 56-57);

ou même à l'église dans « Un suisse » :

Narcisse, un élève modèle, est fier d'avoir capturé un suisse (tamia) qu'il a réussi à dresser. Au catéchisme du dimanche, le curé est interrompu par des rires et, irrité, en demande la cause : une fillette répond : «C'est Narcisse qui montr' son suisse ! » (1906, p. 15-16; 1928, p. 67-68)

Le double sens se retrouve dans la bouche du curé dont « L'Obole » paraît peu généreuse à l'indigent :

Un mendiant, mécontent du sou que son curé lui a donné, dit pour lui-même : «J'vas faire loin avec ça ! » Le curé, qui l'a surpris, lui donne un deuxième sou : «Tenez! vous pourrez faire un peu plus loin !» (1916, p. 113-114)

Ou enfin dans les propos innocents d'une jeune mère en déplacement dans « Pour le conducteur» : 
Dans un tramway, une femme doit allaiter son bébé. Bientôt désaltéré, l'enfant babille et sourit. « Mais la mère veut qu'il finisse » et le menace : «Si tu t'dépêches pas, mon cœur! M'a l'donner au conducteur! » (1928, p. 21-22)

Faute de données comparables, ce premier échantillonnage, établi afin d'illustrer les divers types de jeux de mots privilégiés par Régis Roy pour divertir ses lecteurs, procure déjà des indices de la nature paysanne de ses récits. Pour valider plus solidement l'affirmation qu'ils sont vraiment des « récits du terroir », c'est-àdire que leur source est orale, examinons-en maintenant quelques cas probants. Au moins deux douzaines des récits mis en vers par Régis Roy pourraient faire l'objet d'une confrontation à des variantes attestées dans la tradition orale canadienne-française. Toutefois, pour les fins de cette vérification, une huitaine de récits, dont nous possédons des versions avérées, suffiront. Au terme de cet exercice, on saura si les ingrédients de son humour sont vraiment de nature populaire.

\section{II - EXAMEN COMPARATIF D'UN CHOIX DE CONTES}

\section{A. Les Contes}

À part les jeux de mots signalés plus haut, les proses poétiques de Régis Roy tirent profit de récits facétieux divers : contes de sot, ruses, quiproquos et calembours animent sur le ton de la plaisanterie cette série de fabliaux.

\section{LA NOËL ${ }^{25}$}

C'est la veille de Noël.

Le froid est sec, vif, cruel.

Une pauvre mendiante

À la tête branlante,

Un panier sous le bras,

Ne sait où tourner ses pas.

On le voit, elle est étrangère

25. Régis Roy, L'Épluchette, op. cit., 1916, p. 111-112. Au total, quatre reproductions de ce texte ont été repérées : tiré de son premier recueil Les Joyeux Petits Contes canadiens, op. cit., 1906, p. 30-32, il a d'abord paru dans Le Canard, Montréal, 10 janvier 1903, p. 6, puis, l'année de sa publication dans L'Épluchette, il a été repris dans Le Canard, Montréal, 24 décembre 1916, p. 10. 
Dans le quartier.

Vient à passer un charretier

Qui la tire de misère

En lui conseillant de heurter

À telle maison voisine ;

Ce qu'elle fait sans hésiter,

Se dirigeant vers la cuisine

Située à l'arrière.

C'était un presbytère.

La vieille frappe : toc ! toc !

La porte s'ouvre et la servante

Du curé dit :- Saint Roch,

Not' patron, une mendiante

Encore ! Ça n'finira plus.

Mais ça fait rien, entrez la « mère »!

Vous n'êtes pas la première,

Et vous ne serez pas la dernière.

La misère est grande, Jésus!

Et faut soulager l'infortune ;

Mais on ne peut donner beaucoup,

Il en vient trop tout d'un coup !

Si c'était rien que quéqu'une...

Mais la «mère » quel est votre nom ? $\quad 30$

- C'est la Noël, qu'elle répond.

- Ah ! dit Simplice, la servante,

À la pauvre mendiante,

Dans c'cas-là, ça change tout ;

[Et j'ai d'aut' chose pour vous $;{ }^{26}$ ]

Attendez un petit bout,

Et Simplice laissa la vieille.

Elle revint bientôt portant

Une dinde sans pareille :

Un gal[1]inacé géant!

- M'sieu l'curé m'a dit : « Simplice,

Sers [serre] ben la dinde que v'là !

C'est pour la Noël, tu sais, là !

- Ah! que Dieu vous bénisse !»

26. Vers de 7 pieds [34a] restauré d'après la version du Canard (1903) et des Joyeux Petits Contes canadiens (1906). Notons qu'une dizaine de détails (ponctuation, mots remplacés, temps des verbes modifiés) diffèrent des versions antérieures. 
Dit la gueuse emportant l'oiseau.

Noël pour elle fut très beau.

\section{Commentaires et comparaison}

« La Noël » est un poème constitué d'une série de 45 (46) vers en apparence isométrique, mais dont la mesure hésite entre des vers de sept pieds $(20 \mathrm{v}$.) et de huit pieds ( $20 \mathrm{v}$.) ; il présente aussi quelques vers plus courts (un vers de quatre pieds et trois de six pieds) et d'autres plus longs (deux de neuf pieds) ${ }^{27}$. Techniquement, sa structure poétique est défectueuse.

Le scénario de cette histoire tient en quelques mots : un charretier recommande à une mendiante étrangère d'aller frapper à la porte du presbytère qui est fort sollicité en cette veille de Noël. La servante Simplice l'accueille d'abord avec contrariété ; puis, apprenant que la miséreuse se nomme la Noël, elle s'empresse de lui remettre la dinde que le curé lui avait expressément prescrit de conserver « pour la Noël », ce qui fit, à n'en pas douter, l'affaire de la pauvre vieille.

Le récit de Régis Roy s'arrête là. La suite n'étant pas donnée, on présume que le curé, privé de la dinde qu'il réservait pour le réveillon ou le souper du jour de Noël, ne prisa guère la bévue de sa servante au prénom pourtant prédestiné.

Cette farce est bien connue dans la tradition orale de la francophonie. La collection franco-ontarienne du père Germain Lemieux en compte trois versions; on notera, dans le résumé de l'exemple retenu, qu'il propose une conclusion dont le récit de Roy est dépourvu.

\section{Janvier, Février et Mars}

Un cultivateur pauvre a fait boucherie pour l'hiver. Il explique à sa femme qu'il entend garder un cochon pour janvier, un deuxième pour février et un troisième pour mars, et saler le reste. Pendant que la viande refroidit, le mari s'absente. Survient un homme. La femme lui demande son nom : « Je m'appelle

27. Le compte des syllabes est le suivant : 4 pieds (v. 8$) ; 6$ pieds (v. $4,16,19)$; 7 pieds (v. 1, 2, 3, 5, 6, 10, 12, 14, 17, 23, 28, 29, 33, 34, [34a], 38, 39, 40, 41, 43), 8 pieds (v. 7, 9, 11, 13, 15, 18, 20, 21, 22, 25, 26, 27, 31, 32, 35, 36, 37, 42, 44, 45) ; 9 pieds (v. 24, 30). 
Janvier ». La femme qui est sotte lui donne un cochon, car, lui dit-elle, " il y avait un cochon pour Janvier, un autre pour Février et l'autre pour Mars ». L'homme profite de la situation et se représente sous le nom de Février, puis de Mars, de sorte qu'il s'empare des trois cochons. Quand, à son retour, le mari apprend son aventure, il n'en revient pas et la traite de « maudite folle ! » Il décide de poursuivre les voleurs avec sa femme qui passe par un autre chemin. En chemin, elle trouve une peau de bœuf avec la tête et l'emporte contre l'avis de son mari. En forêt, ils aboutissent à une clairière, rendez-vous des voleurs, et ils se cachent dans un arbre. Arrivent trois voleurs qui se préparent une soupe. Le cuisinier souhaite avoir du sel : la femme, ne pouvant se retenir, « lâche de l'eau » [urine]; puis il demande de la muscade - elle « rabat sa robe : proutte ! dans la soupe $» \ldots$ « Le bon Dieu nous aime ! » disent-ils. Mais, en partageant l'argent volé, les larrons se querellent. La femme jette alors sa peau de bœuf en criant : " C'est le diable qui sort de l'enfer pour vous poigner! » Les voleurs s'enfuient, abandonnant les 3000 dollars que le couple récupère. Les époux se sont raccordés et vivent ensemble depuis. ${ }^{28}$

Mise à part la finale, le scénario se développe en parallèle dans les deux versions : la bêtise de la femme, servante ou épouse, engendre le malentendu où elle interprète faussement un moment (Noël, janvier, février, mars) comme le nom d'un individu à qui elle donne la viande (dinde, cochon) à conserver.

De toute évidence, il s'agit d'un conte de sot, dont le répertoire est abondant parmi les contes à rire. Celui-ci repose sur un quiproquo, un procédé fort ancien et fréquent au théâtre, dont la Farce de maître Pierre Pathelin, considérée comme la plus célèbre pièce comique du théâtre français, témoigne dès le $\mathrm{XV}^{\mathrm{e}}$ siècle. Si, dans la version Roy, la méprise de la servante bénéficie inopinément à une mendiante, elle sera plutôt exploitée dans la version Lemieux à l'avantage d'un profiteur qui aura repéré

28. Collection Germain Lemieux, enreg. 1442, conté le 22 novembre 1959, à Cache-Bay, Ontario, par Maurice Prud'homme (72 ans) de Sturgeon-Falls. Conte appris dans les chantiers, vers 1911. Conte terminé par Émile Roy (74 ans) de CacheBay. Cf. Germain Lemieux, Les vieux m'ont conté, Montréal, Éditions Bellarmin, et Paris, Maisonneuve et Larose, 1977, vol. 9, n 17, « Janvier, Février et Mars », version remaniée, p. 245-248, version originale, p. 249-253. 
Tableau 1 - « La Noël » L'Épluchette, 1916 (p. 111-112)

\begin{tabular}{|c|c|c|c|}
\hline & Versions & Régis Roy & Germain Lemieux, enreg. 1442 \\
\hline & Protagonistes & & \\
\hline & Homme & Curé & Mari cultivateur \\
\hline & Femme & Simplice, la servante du curé & Sa femme qui «était pas mal craquée » \\
\hline & Mendiant & Une vieille mendiante & Un gars qui se présente à la porte \\
\hline & $\begin{array}{l}\text { I - La recommandation } \\
\text { avant le départ }\end{array}$ & $\begin{array}{l}\text { C'est la veille de Noël. } \\
\text { [...] } \\
\text { - M'sieu l'curé m'a dit « Simplice, } \\
\text { Sers [serre] ben la dinde que v'là ! } \\
\text { C'est pour la Noël, tu sais, là ! }\end{array}$ & $\begin{array}{l}\text { Le mari a fait boucherie « dans l'automne avant } \\
\text { les neiges ». } \\
\text { Il veut garder un cochon pour janvier, un autre } \\
\text { pour février et un troisième pour mars, et saler } \\
\text { les autres. }\end{array}$ \\
\hline & II - La visite du mendiant & $\begin{array}{l}\text { C'était un presbytère. } \\
\text { La vieille frappe : toc ! toc ! } \\
{[\ldots]} \\
\text { Mais la « mère » quel est votre nom? } \\
\text { - C'est la Noël, qu'elle répond. } \\
{[\ldots]} \\
\text { Et Simplice laissa la vieille. } \\
\text { Elle revint bientôt portant } \\
\text { Une dinde sans pareille } \\
\text { Un gal[1]inacé géant ! }\end{array}$ & $\begin{array}{l}\text { - Puis votre nom, elle dit, vous monsieur? } \\
\text { - Mon nom, il dit, moi, c'est Janvier! } \\
\text { Elle lui donne un cochon en lui expliquant que } \\
\text { son mari en a préparé un autre pour Février et } \\
\text { Mars. } \\
\text { L'homme revient sous le nom de Février, puis } \\
\text { de Mars, et obtient les trois cochons. }\end{array}$ \\
\hline 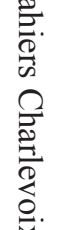 & III - La conclusion & $\begin{array}{l}\text { - Ah ! que Dieu vous bénisse ! » } \\
\text { Dit la gueuse emportant l'oiseau. } \\
\text { Noël pour elle fut très beau. }\end{array}$ & $\begin{array}{l}\text { Au retour du mari, elle lui raconte cette visite. } \\
\text { - Je te pensais jamais folle de même. Câline } \\
\text { que t'es folle! } \\
\text { Ensemble, ils partent à la poursuite des voleurs. } \\
\text { [ATU } 1653: \text { le couple récupère les } 3000 \$ \text { que } \\
\text { des voleurs se divisaient et il se raccorde.] }\end{array}$ \\
\hline
\end{tabular}


une victime simplette. C'est que ce conte du niais berné figure au catalogue international dans le cycle de l'homme astucieux ATU 1525-163929, souvent fourbe, qui n'hésite pas à dépouiller quiconque de son bien par quelque traîtrise.

En Belgique francophone, George Laport signale deux versions wallonnes dans son catalogue des contes populaires. Il résume la première sous le type 1541, Le Jambon de l'Août : «On réserve un jambon pour l'Août. Une servante peu intelligente se demande ce que cette expression signifie. Un voleur entre à la ferme et se fait passer pour l'Août. La servante lui remet le jambon. En échange, le voleur lui donne un bâton de malice..$^{30} \gg$ Et la seconde sous le type *1541 A, Le Gamin et les trois cochons : « Une femme qui a un fils niais l'envoie aux champs avec trois cochons. Elle lui recommande de bien les garder, car l'un est pour Pâques, l'autre pour la Pentecôte et le troisième pour Noël. Le gamin rencontre trois hommes, dont l'un se dit Pâques, le deuxième Pentecôte, le troisième Noël. L'enfant remet un cochon à chacun d'eux. Une raclée le récompense d'avoir écouté sa mère. ${ }^{31}$ » Du côté flamand, Maurits de Meyer en rapporte quatorze versions sous le type 1541 Le Long Hiver : «L'homme a dit à sa femme qu'on réserverait le jambon (bourse d'argent) pour le long hiver (pour plus forte misère - Pâques ou la Pentecôte), [un] filou se fait passer pour le long hiver. ${ }^{32}$ »"

La perte de la viande précieuse crée alors un déséquilibre que le dénouement des contes populaires se charge de redresser. Pour ce faire, la narration se prolonge couramment par un autre épisode, celui qu'on a précédemment lu dans la version Lemieux : le type Atu 1653 Les Brigands sous l'arbre : ceux-ci sont « mis en fuite

29. Hans-Jörg Uther, The Types of International Folktales. A Classification and Bibliography, Helsinki, Academia Scientiarum Fennica, «FF Communications » 285, 2004, 3 tomes [désormais ATU d'après le patronyme des auteurs successifs : AarneThompson-Uther].

30. George Laport, Les Contes populaires wallons, Helsinki, Academia Scientiarum Fennica, « FF Communications » 101, 1932, p. 115-116.

31. Ibid., p. 116.

32. Maurits de Meyer, Le Conte populaire flamand, Helsinki, Academia Scientiarum Fennica, «FF Communications » 203, 1968, p. 117. 
par la peau d'une vache que [l'épouse] laisse tomber sur eux ${ }^{33} »$. Présent dans six des quatorze versions flamandes, ce procédé s'avère une combinaison habituelle pour ce type généralement recensée dans le monde ${ }^{34}$.

\section{Les DEUX CHATS ${ }^{35}$}

Pour rentrer la moisson,

Vivement, en saison,

Jean prit garçons de ferme,

Qu'il fit travailler ferme.

La récolte paya bien

Et Jean encaissa plein

Un pied de bas de laine

De billets et d'argent.

Dans sa chambre, Gros-Jean

Avait une cachette,

Cachette très secrète

Pour celer son trésor.

Ainsi voulut le sort

Que les garçons de ferme

Engagés pour ce terme,

$\mathrm{S}[\mathrm{u}] \mathrm{rent}$ que leur patron

Avait dans la maison

Somme très rondelette,

Et qu'il avait cachette

Pour entasser ses sous.

Tout sens dessus dessous, Ils auraient bien pu mettre,

Mais il veillait le maître,

Et pour risquer le coup,

C'était risquer beaucoup.

$\mathrm{Ce}$ que les deux compères

Qui point ne désespèrent

Ne veulent point encore

Brusquer pour le trésor.

Mais à force de faire

Enquête en cette affaire,

33 Ibid., p. 122-123.

34. Hans-Jörg Uther, op. cit., T. II, p. 279.

35. Régis Roy, L'Épluchette, op. cit., 1916, p. 85-88. 
Ils apprirent enfin

Où le compère fin

Cachait son bas de laine.

À l'heure où la nuit pleine

Étend son voile noir

Qu'on peut à peine y voir,

Où cette sombre fée

Nous livre au dieu Morphée.

Voici qu'à pas de loup

Viennent tenter leur coup

Les deux garçons de ferme.

Leur cœur est vaillant, ferme.

Ces gens ne craignent point.

Ils marchent avec soin

Celui qui vient en tête

À la porte s'arrête

De la chambre de Jean.

Seul un [ry]thme pesant

De poumons en cadence,

Souffle dans le silence

De la paisible nuit ;

C'est un rassurant bruit,

Car Jean et son épouse

Dorment. Le coup de douze

Résonne clairement, En bas, et lentement,

À la vieille pendule.

L'un des voleurs module

Un pst d'attention,

Puis à son compagnon

Glisse bas à l'oreille :

- Là d'dans, l'vieux et la vieille

Dorment d'un lourd sommeil,

Ou quéqu' chos' de pareil !

J'vais entrer dans 1[a] place,

Puis après un espace

De quelques instants, toi,

$\mathrm{Tu}$ viendras après moi.

Pas de bruit, et fais vite. 
Et surtout je t'invite

À m'imiter en tout.

Ensuite, à pas de loup

Dans la pièce il pénètre.

Un ais disjoint peut-être,

Sous le pied du voleur,

Lors, gémit de douleur,

Ce bruit dans le silence

Nocturne est plus intense

Et réveille presto

La vieille à son dodo ;

Un peu terrifiée

Elle s'est écriée ;

- Qui... qui... qui... sque c'est ça ?

L'homme imite le chat :

- Miaou! - Bah! fit-elle

C'est not' chatte Fidèle,

Je m'alarmais à tort,

Rendormons-nous encor!

L'autre voleur qui guette

Au seuil de la chambrette,

Juge le moment pour

Pénétrer à son tour,

Et se glisse avec aise

Lorsqu'il heurte une chaise.

La vieille alors bondit

Presque hors de son lit

Et s'écrie apeurée :

- Jean, qu'est-ce que c'est ça ?

Le voleur, vrai bêta,

La voix pleine, assurée,

Répondit : C'est l'autr' chat !

\section{Commentaires et comparaison}

À l'exception du cinquième vers, qui compte un pied de trop - et que l'auteur aurait aisément pu retrancher par l'élision du -e de récolte, technique qu'il pratique ailleurs (v. 63, 65, 84, 87, 102) -, le poème, divisé en deux strophes, se compose de 102 hexasyllabes réguliers à rimes plates ; bizarrement, le vers 7 ne rime avec 
aucun autre et les cinq derniers vers présentent des rimes embrassées (v. 98-101) suivies d'une rime supplémentaire (v. 102).

Après avoir embauché deux employés pour la récolte et fait ainsi de bonnes affaires, Gros-Jean cache son «bas de laine » dans la chambre à coucher. Mais ses serviteurs finissent par le découvrir et projettent de le dérober. Cette mise en situation forme la première strophe (v. 1-34) et prépare l'action de la seconde (v. 35-102). Une nuit, pendant que le patron dort profondément avec son épouse, le premier voleur pénètre à pas feutrés dans la chambre. Mais une planche disjointe bruit et réveille la dame : «Qui est là ? ». L'esprit présent, le voleur miaule et, croyant que c'est la chatte, dame Gros-Jean se rendort. À son tour, le second voleur, un nigaud, entre et heurte une chaise. Devant la dame qui s'écrie, il veut imiter son complice et répond : «C'est l'autre chat! »

On reconnaît bien le récit pour lequel Stith Thompson a créé en 1961 le type 1363* Le Deuxième Chat pour accueillir les seules versions canadiennes-françaises alors connues. Dans sa révision du catalogue international, en 2004, Hans-Jörg Uther a fusionné cette facétie avec le type 1341A* Le Voleur en chien dont la finale s'achève par : "C C'est moi, le chien ${ }^{36}$. Luc Lacourcière a recueilli une variante de ce fabliau qui porte le même titre que la version Roy.

\section{Les deux chats}

Deux gars allaient voir la même fille. Une soirée, quand ils ont été voir la jeune fille, il commençait à mouiller. Puis le père leur a demandé pour rester coucher à la maison. Ils ont accepté.

Vers minuit, après qu'ils ont été couchés, le plus beau des deux gars a dit à l'autre qu'il allait aller voir la fille dans sa chambre, Il a sorti de la chambre. Quand il a passé devant la chambre du père de la fille, le plancher a commencé à craquer. Le père a crié :

$$
\text { - Qui c'est qui est là ? }
$$

36. La seule version nord-américaine que cite ce dernier n'a toutefois rien à voir avec ce type. Voir le récit franco-louisianais n 56 « Le Commis-voyageur » publié par Barry-Jean Ancelet, Cajun and Creole Folktales, The French Oral Tradition of South Louisiana, Jackson, University Press of Mississippi, 1994, p. 101-102. 
Tableau 2 - « Les deux chats » L'Épluchette, 1916 (p. 85-88)

\begin{tabular}{|c|c|c|c|}
\hline Versions & Régis Roy & Lacourcière, ms. 49 & JPP, enreg. 1989 \\
\hline Protagonistes & & & \\
\hline Homme & Gros-Jean, cultivateur & Père & Père \\
\hline Femme & Son épouse & Sa fille & $\begin{array}{c}\text { Sa fille insiste pour accueillir les } \\
\text { étrangers }\end{array}$ \\
\hline Hôtes/invités & Deux garçons de ferme & Les deux prétendants & Trois Nioufis \\
\hline I - L'accueil à la maison & $\begin{array}{l}\text { Pour rentrer la moisson, }[\ldots] \\
\text { Jean prit garçons de ferme }\end{array}$ & $\begin{array}{l}\text { À cause de la pluie, le père leur offre } \\
\text { l'hospitalité pour la nuit }\end{array}$ & $\begin{array}{l}\text { Ils demandent l'hospitalité durant } \\
\text { une tempête }\end{array}$ \\
\hline II - Le délit & $\begin{array}{l}\text { [Voler la « somme très rondelette » de leur } \\
\text { patron. Ils trouvent le lieu où il « cachait } \\
\text { son bas de laine »: sa chambre] } \\
\text { À l'heure où la nuit pleine [...] } \\
\text { Voici qu'à pas de loup [les compères] } \\
\text { Viennent tenter leur coup } \\
\text { "Tu viendras après moi. } \\
\text { Pas de bruit, et fais vite. } \\
\text { Et surtout je t'invite } \\
\text { À m'imiter en tout. » [...] } \\
\text { [La vieille se réveille au bruit du premier } \\
\text { intrus :] } \\
\text { L'homme imite le chat ! / } \\
\text { «- Miaou! - Bah! fit-elle / } \\
\text { C'est not' chatte Fidèle » } \\
\text { [Le second réveille encore la vieille] } \\
\text { Le voleur, vrai bêta, } \\
\text { La voix pleine, assurée, } \\
\text { Répondit : «C'est l'aut' chat !» }\end{array}$ & $\begin{array}{l}\text { Aller voir la fille dans sa chambre } \\
\text { Le plus beau des deux va voir la fille. } \\
\text { Une planche « craque » devant la } \\
\text { chambre du père : } \\
\text { - Qui c'est qui est là? dit-il. } \\
\text { Le gars a miaulé comme un chat. } \\
\text { Au retour du premier, le second y va. } \\
\text { Même bruit, même question du père : } \\
\text { Le garçon répond : } \\
\text { «C'est un autre chat. » }\end{array}$ & $\begin{array}{l}\text { Aller à la chambre de la fille «bien } \\
\text { amanchée » } \\
\text { Les trois, à tour de rôle, vont voir } \\
\text { la fille dans son lit. } \\
\text { Le père se réveille au bruit que fait } \\
\text { le premier : "- Qui est là? } \\
\text { - Miaou. - Ah! c'est le chat. » } \\
\text { Il passe sans problème et couche } \\
\text { avec la fille. } \\
\text { Même chose pour le deuxième } \\
\text { À la question du père, le troisième } \\
\text { répond : } \\
\text { «C'est le chat. » }\end{array}$ \\
\hline III - La conclusion & [Échec de la tentative de vol] & Ça l'a fait déclarer. & $\begin{array}{l}\text { [Le Nioufi stupide échoue après le } \\
\text { succès de ses deux compagnons] }\end{array}$ \\
\hline
\end{tabular}


Le gars a miaulé comme un chat. Puis il a été voir la fille. Une heure après, il a été trouver son chum dans sa chambre. L'autre gars avait vu l'aventure se dérouler. Il a pensé : « Je vas faire la même chose ». Quand il a arrivé devant la chambre du père de la fille, le plancher a encore craqué. Le père a crié :

- Qui est-ce qui est là?

Le garçon a dit :

- C'est un autre chat.

Ça l'a fait déclarer. ${ }^{37}$

Nous avons aussi recueilli la même histoire, remodelée selon les populaires histoires de Nioufis ${ }^{38}$, à la fin des années 1970.

Trois Nioufis demandent l'hospitalité durant une tempête C'était une fois trois Nioufis. Il y avait une tempête qui commençait dehors. Les trois Nioufis cognent à une porte. Le père arrive, il dit :

- Oui.

Un Nioufi arrive, il répond :

- Pardon monsieur, est-ce qu'on pourrait passer la nuit ici à cause de la tempête ?

Le bonhomme dit :

- Ah! Je le sais pas.

Il y avait sa fille, une fille bien amanchée. Elle arrive, elle dit :

- Envoye donc, papa, envoye donc.

Le père dit :

- Ah, c'est correct.

Là, les trois Nioufis, pour aller à la chambre de la fille, pour aller voir la fille, il fallait qu'ils passent devant la chambre du père. Là, le premier Nioufi, il arrive, il sort, il s'en va. Là, les planches craquaient à cause que ça faisait du bruit. Le père dit :

- Qui est-ce qui est là ?

- Miaou!

- Ah, c'est le chat, correct.

Là, le gars s'en va dans la chambre de la fille, il se passe tout ça.

Le deuxième Nioufi arrive, il sort de la chambre, il s'en vient, il faisait du bruit, il écorniflait. Il arrive, le père dit :

37. Collection Luc Lacourcière, ms. 49, version de Delmont Chiasson, 17 ans, de Shippagan, Nouveau-Brunswick, contée le 24 juin 1954.

38. Transcription francisée du gentilé abréviatif Newfie, attribué aux habitants de Terre-Neuve, en anglais Newfoundlander; dans les blagues, les Nioufis sont des personnages sots. 
- Qui est-ce qui est là ?

- Miaou!

- Ah! C'est encore le chat, c'est correct.

Il se la passe puis tout ça.

Le troisième Nioufi, le plus fou de la gagne [de gang, groupe], il arrive, il s'en vient là, en faisant du bruit, puis tout. Là il arrive, il dit :

- Qui est ce qui est là?

Le Nioufi répond:

- C'est le chat ! ${ }^{39}$

Les divers éléments de comparaison sont résumés dans le tableau synoptique suivant.

Une autre version, incomplète celle-là, situe l'action dans un hôtel. L'hôtelier interdit aux deux clients de monter à l'étage supérieur pour voir sa fille. Le premier parvient à la visiter, malgré la planche qui a « craqué », car il a miaulé. Le lendemain, le second s'essaie. Mais quand on lui demande «Qui est là ? », il répond : «C'est le chat. $»^{40}$

\section{PAS tous À LA FoIs ${ }^{41}$}

Gros-Jean pressé vint en ville à cheval

Pour vaquer à des affaires

Qui lui causaient bien des misères.

Après s'être donné du mal

Il eut gain de cause,

Et, pour célébrer ce succès,

Fallait bien prendre " quèque chose ».

Mais... il en prit à l'excès

Et quand sonna l'heure

De retourner à sa demeure,

Il ne put monter son coursier

Malgré plusieurs tentatives.

Pour avoir de l'aplomb, que moins lourd soit son pied

39. Collection Jean-Pierre Pichette, enreg. 1989, version de François Mercier, école $\mathrm{M}^{\mathrm{gr}}$ de Laval, Québec, recueillie le 7 mars 1978. Après lecture de ce texte, notre confrère Yves Frenette a noté : « Cette histoire circulait beaucoup à Cap-Santé autour de 1970. Mon père ou un de ses frères la racontait. » (20 novembre 2017).

40. Collection Jean-Pierre Pichette, ms. 1414, version de Benoît Desbiens, Charlesbourg, Québec, notée en octobre 1977.

41. Régis Roy, L'Épluchette, op. cit., 1916, p. 11-12. 
Bacchus reçoit ses récidives.

Gros-Jean moins ferme que jamais

N'en peut mais,

Perdant patience, il s'écrie :

- Aidez-moi, sainte Marie!

Il essaie encor

Mais n'est pas plus fort.

De fait sa jambe est moins raide.

Alors, à son aide,

Il appelle son patron :

- Bon saint Jean, aidez-moi don'!

Il veut sauter en selle,

Trébuche et chancelle ;

Il n'en peut guère, il n'en peut plus !

- Secourez-moi, mon Jésus!

Par un dernier effort, hop ! il pique une tête

Pardessus la bête.

Il se relève un peu meurtri

Et remarque, marri :

- Saint Jean, Jésus et Marie,

Pas tous à la fois, j'vous en prie !

\section{Commentaires et comparaison}

Sans patron véritable, ce poème compte 34 vers irréguliers, de trois à douze syllabes, qui s'enchaînent ainsi : rimes embrassées (v. 1-4), puis croisées (v. 5-8), suivies (v. 9-10) et croisées (v. 11-14) avec retour aux rimes suivies deux à deux (v. 15-30) et rime identique pour les quatre derniers vers (v. 31-34).

Exceptionnellement, Gros-Jean est l'unique acteur d'une mésaventure dont il s'avère par défaut lui-même la cause. Ayant trop bu pour célébrer le succès de ses affaires, il est incapable de remonter en selle au moment de retourner chez lui. Après des essais infructueux, il invoque la Vierge, puis saint Jean son patron, en vain. Demandant finalement l'aide de Jésus, il s'élance pardessus son cheval et tombe au sol. Désemparé, il reproche aux saints d'avoir agi de concert : «Pas tous à la fois, je vous en prie. »

Les exemples de croyants qui n'hésitent pas à demander l'intercession des cieux pour les assister en temps d'épreuve 
étaient courants dans la piété populaire d'autrefois, comme ils le sont encore de nos jours. S'ils empruntent ordinairement la voie de la prière, qui est une oraison de demande, certains préfèrent parfois la magie et ses pratiques superstitieuses, qui visent plutôt à contraindre les forces surnaturelles, dieux et diables, de leur octroyer les faveurs recherchées. À côté de nombreuses coutumes bien innocentes, comme placer son chapelet sur la corde à linge pour qu'il fasse beau le jour de son mariage, ou porter sur soi fétiche ou porte-bonheur, certaines actions sont ambiguës. L'expérience de cette dame qui, ne soutirant pas la faveur demandée de saint Joseph, l'avait mis en punition en tournant son image et sa statue face au mur, illustre une foi forte, voisine de la magie. Et elle ajoutait confiante : "Ça ne sera pas long. Il sera tellement fâché qu'il va m'accorder ce que je lui demande. S'il a la tête dure, je l'ai encore plus dure. ${ }^{42} \gg$ On relève aussi des contes populaires de cette nature. Le conte type *1644, proposé par George Laport pour ses contes wallons, est de ceux-là.

*1644. Le Conscrit et saint Joseph. Au moment d'aller tirer au sort, la mère conseille à son fils d'embrasser la statue de saint Joseph. Au lieu de suivre cet avis, le conscrit redargue [réprimande] le saint de façon assez grossière. Scandalisée, la mère demande pardon et prie devant la statue. Le jeune homme revient écarté par le tirage. Sa mère remercie saint Joseph, pendant que son fils conclut : « Je sais comment il faut parler à ces gens-là ! $»^{43}$

Cette conclusion rappelle cette version du type ATU 1643 L'Argent à intérieur de la statue recueillie en 1978.

Un garçon sot, qui doit conduire une vache à l'abattoir, suit mal les instructions de son père ; par mégarde, il entre dans une église et confie la bête au bedeau qui promet de le payer le lundi suivant. Quand le garçon revient, le bedeau a oublié ; prenant la statue de saint Antoine pour le bedeau, il réclame

42. Anecdote personnelle, citée de mémoire, qui remonte au milieu des années 1970 à Québec.

43. George Laport, op. cit., p. 123-124. Référence aimablement suggérée par Josiane Bru, ethnologue responsable du Catalogue $d u$ conte populaire français, Centre d'anthropologie, Université de Toulouse. 
son argent. N'obtenant pas de réponse, il frappe la statue qui se brise. Il empoche l'argent du tronc et s'exclame : "Quand on te brasse, il dit, tu payes, hein? $»^{44}$

Pour revenir au récit de Régis Roy, qui n'est pas encore classé au catalogue international, nous possédons la variante qui suit.

\section{Sacreur : embarquez pas tous sur le même bord}

Une fois, c'était un gars qui conduisait une grosse van, un gros camion là, puis il avait une méchante habitude de sacrer. Ça fait qu'un moment, je suppose qu'il était allé à la confesse puis le prêtre lui a dit :

- Écoute donc là. Il faudrait que tu te corriges de ça. À la place de sacrer, quand tu viens pour sacrer, dis donc : saint Pierre, embarquez avec moi. Tu conduis une van, ça va bien aller. Quand tu auras encore envie, tu diras : saint Jude, embarquez avec moi.

Ça fait que le gars, il prend ça. Il dit :

- Je vais essayer ça, monsieur le curé. Tout d'un coup que ça marche : ça me fera une mauvaise habitude de corrigée.

Ça fait que le gars s'en va sur son camion. Puis là, il descendait à la Malbaie. Puis il y a des méchantes côtes dans ce coin-là. Un moment donné, il te poigne un tournant un peu raide. Il dit :

- Saint Pierre, embarquez donc avec moi!

Ça fait que ça passe comme ça. Il avait réussi à [ne] pas sacrer. Il en fait encore un bout. Encore un autre tournant puis, là, dans la côte, quelqu'un vient pour le dépasser. Il dit :

- Sainte Vierge, embarquez donc avec moi !

Ça fait que ça continue. Puis c'était une côte qui descendait, là, puis il avait de l'allure, il avait pris de la vitesse là, il était plus capable de s'arrêter. Puis il arrive dans le bas de la côte puis il y avait justement une espèce de nono qui était stationné là. Ça fait que là, il avait pas le choix, le gars là, il a été obligé de se tasser. Ça fait que, là, il poigne le clos. Ah bien, le gars était assez en maudit. Il dit :

- Viarge! je vous ai fait embarquer avec moi, je vous ai pas dit de tous embarquer sur le même bord, par exemple $!^{45}$

44. Collection Jean-Pierre Pichette, enreg. 840, « L'Histoire de la vache », résumé de la version de François Dorval, 55 ans (né en 1923), recueillie à Saint-Léonde-Standon, Québec, le 10 août 1978.

45. Collection Jean-Pierre Pichette, enreg. 502, version de Jean-Pierre Pichette, 
Tableau 3 - « Pas tous à la fois » L'Épluchette, 1916 (p. 11-12)

\begin{tabular}{|c|c|c|}
\hline Versions & Régis Roy & JPP, enreg. 502 \\
\hline \multicolumn{3}{|l|}{ Protagonistes } \\
\hline Homme & Gros Jean & Camionneur sacreur d'habitude [qui jure] \\
\hline Autre & Aucun : il est seul & Prêtre confesseur \\
\hline I - Le problème à régler & $\begin{array}{l}\text { Gros-Jean pressé vint en ville à cheval } \\
\text { Pour vaquer à des affaires [...] } \\
\text { Et, pour célébrer ce succès, [il prit un coup] à } \\
\text { l'excès [... Mais au retour :] } \\
\text { Il ne put monter son coursier. }\end{array}$ & $\begin{array}{l}\text { Il reçoit ce conseil de son confesseur: } \\
\text { « À la place de sacrer, dis donc : } \\
\text { saint Pierre, embarquez avec moi [...] } \\
\text { saint Jude, embarquez avec moi. }\end{array}$ \\
\hline II - Les invocations & $\begin{array}{l}\text { Perdant patience, il s'écrie : } \\
\text { - Aidez-moi, sainte Marie ! [...] } \\
\text { Il appelle son patron : } \\
\text { - Bon saint Jean, aidez-moi don' ! [...] } \\
\text { Il n'en peut guère, il n'en peut plus ! } \\
\text { - Secourez-moi, mon Jésus! }\end{array}$ & $\begin{array}{l}\text { En difficulté dans les côtes abruptes de la } \\
\text { Malbaie, il appelle : } \\
\text { - Saint Pierre, embarquez donc avec moi! } \\
\text { Plus tard : } \\
\text { - Sainte Vierge, embarquez donc avec moi ! }\end{array}$ \\
\hline III - L'échec expliqué & $\begin{array}{l}\text { Par un dernier effort, hop ! il pique une tête } \\
\text { Pardessus la bête. } \\
\text { Il se relève un peu meurtri } \\
\text { Et remarque, marri : } \\
\text { - Saint Jean, Jésus et Marie, } \\
\text { Pas tous à la fois, j'vous en prie ! }\end{array}$ & $\begin{array}{l}\text { Incapable de s'arrêter dans la côte à cause } \\
\text { d'une auto mal stationnée, il jure : } \\
\text { - Viarge ! je vous ai fait embarquer avec moi, } \\
\text { [mais] je vous ai pas dit de tous embarquer sur } \\
\text { le même bord! }\end{array}$ \\
\hline
\end{tabular}


Comparée au fabliau de Régis Roy, notre histoire oppose deux personnages, un camionneur qui a la mauvaise habitude de jurer et son confesseur qui lui conseille de remplacer ses mots injurieux par des invocations invitant les saints à faire route avec lui. Il en fait ainsi monter quelques-uns à bord jusqu'au moment où son camion s'écrase dans le bas de la côte. Pour marquer sa consternation, son invocation se transforme alors en juron : « Viarge [et non plus Vierge], je [ne] vous ai pas dit de tous embarquer sur le même bord! ». Cette conclusion coïncide avec la finale « Pas tous à la fois, j'vous en prie ! » du conte de l'auteur d'Ottawa.

\section{La VAChe Perdue de Gros-Jean ${ }^{46}$}

Gros-Jean a perdu sa vache, Et malgré qu'il tâche

De la retrouver n'y parvient. Enfin, chez le curé s'en vient Lui demander une annonce

Pour le prône suivant.

D'abord le prêtre y renonce ;

Ce serait scandale, vraiment !

C'est à la porte de l'église

Plutôt que ces choses se font ;

Ce moyen ne paraît pas bon

À Gros-Jean qui point ne le prise ;

Il insiste pour l'autre, mais

Le curé ne voudra jamais.

Cependant... la chose... peut-être...

Pourrait s'arranger... Voyons !

Et le bon, le digne prêtre

Cède en posant des conditions :

« Gros-Jean aime trop la goutte,

Il faudra sur ce s'amender?»

Et quoique cela lui coûte

Il lui faut capituler.

« Ensuite, souvent Gros-Jean, jure, Blasphème quand en boisson;

Il faut qu'il soit meilleur garçon ?»

Notre-Dame-des-Laurentides, Québec, enregistrée le 12 juin 1977.

46. Régis Roy, L'Épluchette, op. cit., 1916, p. 124-126. 
Ne plus sacrer, la chose est sûre,

À s'empêcher de cela

Ce sera peut-être difficile,

Mais enfin, on essaiera.

« Gros-Jean avec sa famille

Devra venir plus souvent

À l'église, à la messe ?»

Jean fait encor cette promesse.

Il attend alors en tremblant

Ce qu'on va demander encore.

Lui demandera-t-on beaucoup ?

Mais non, là, c'est bien tout !

Dans un : Topons-là sonore,

Se clôt l'étrange arrangement.

Le dimanche à l'église

Gros-Jean de tous est la surprise.

Le service saint, cependant

Paraît long à notre pédant ;

Le sommeil le maîtrise,

Dans son banc finalement

Et le gagne rapidement.

Le curé monte en chaire ;

C'est l'heure où le prône se fait.

De l'impudent Gros-Jean, l'affaire

Cause sensation en effet;

Le curé passe à d'autre chose,

Puis à d'autre, quand Gros-Jean

Se réveille soudain et cause

Un scandale. Pensant

Que Caillette est en cause

Voici ce qu'il interpose

Dans le prône du curé,

Qui venait de recommander

Une dame décédée

Récemment. Elle avait possédée

Toutes les vertus :

Travaillante, pas gaspilleuse, Douce, propre et soigneuse.

Ce fut là-dessus

Que Gros-Jean, notre homme 
À sa vache pensant, s'arrache de son somme

Et dit : - M'sieu l'curé, s'il vous plaît !

Dit' donc aussi qu'a donnait ben du lait !

\section{Commentaires et comparaison}

La structure poétique de cette longue strophe de 68 vers est plutôt flottante. Composée principalement d'octosyllabes (32 v.), elle renferme aussi des heptasyllabes $(20 \mathrm{v}$.), des hexasyllabes $(8 \mathrm{v}$. $)$ et des vers de métrique variée ( $4 \mathrm{v}$. de 5 pieds, 2 v. de 9 pieds, $1 \mathrm{v}$. de 10 et $1 \mathrm{v}$. de 12 pieds). L'enchaînement des rimes est à l'avenant : la préférence va aux rimes croisées (v. 5-8, 15-18, 19-22, 27-30, 47-50 et 51-54) et aux rimes embrassées (v. 9-12, 23-26, 31-34, 35-38, 39-42, 61-64), puis aux rimes suivies (v. 1-4, 13-14, 57-60, 65-68); des rimes mélangées apparaissent en deux endroits ( $8 \mathrm{v}$. sur deux rimes, v. 39-46 ; 6 v. sur deux rimes, v. 51-56).

Gros-Jean, catholique à gros grain, peu pratiquant, se tourne vers son curé pour obtenir de l'aide afin de retrouver sa vache perdue. Il ne demande rien de moins qu'une annonce en chaire, au moment du prône. Le curé refuse carrément d'abord, puis en profite pour amadouer l'individu et négocier avec lui un changement de comportement, car Gros-Jean devra s'amender sur trois points précis : son fort penchant pour la boisson, qui le conduit à l'abus de jurons, voire de blasphèmes, et sa faible assiduité à la messe du dimanche. En cela, notre homme porte deux des trois travers du Canadien français que les prédicateurs stigmatisaient sous la triple appellation " champlure, sacrure et créature »; ici, Régis Roy s'abstient d'évoquer le troisième qui concerne la luxure ${ }^{47}$. Gros-Jean n'a pas le choix d'accepter et l'affaire est conclue. Le dimanche suivant, à la surprise générale, il se présente à l'église. Toutefois, gagné par le sommeil, il dort pendant que le prêtre signale la vache disparue ; mais Gros-Jean s'éveille bientôt

47. Jean-Pierre Pichette, Le Guide raisonné des jurons : langue, littérature, histoire et dictionnaire des jurons, Montréal, Quinze, " Mémoires d'homme », 1980, p. 259 : «Le père Lelièvre ([oblat] apôtre du Sacré-Cœur) considérait la sacrure comme l'un des trois vices principaux qu'il fallait combattre ; les deux autres étaient la créature (la femme) et la champlure (la boisson). » Pour d'autres citations, $c f$. " sacrure » dans Le Trésor de la langue française au Québec [www.tlfq.ulaval.ca/ dhfq2/champlure_2006.pdf] (source consultée en ligne le 7 novembre 2017). 
Tableau 4 - « La vache perdue de Gros-Jean » L'Épluchette, 1916 (p. 124-126)

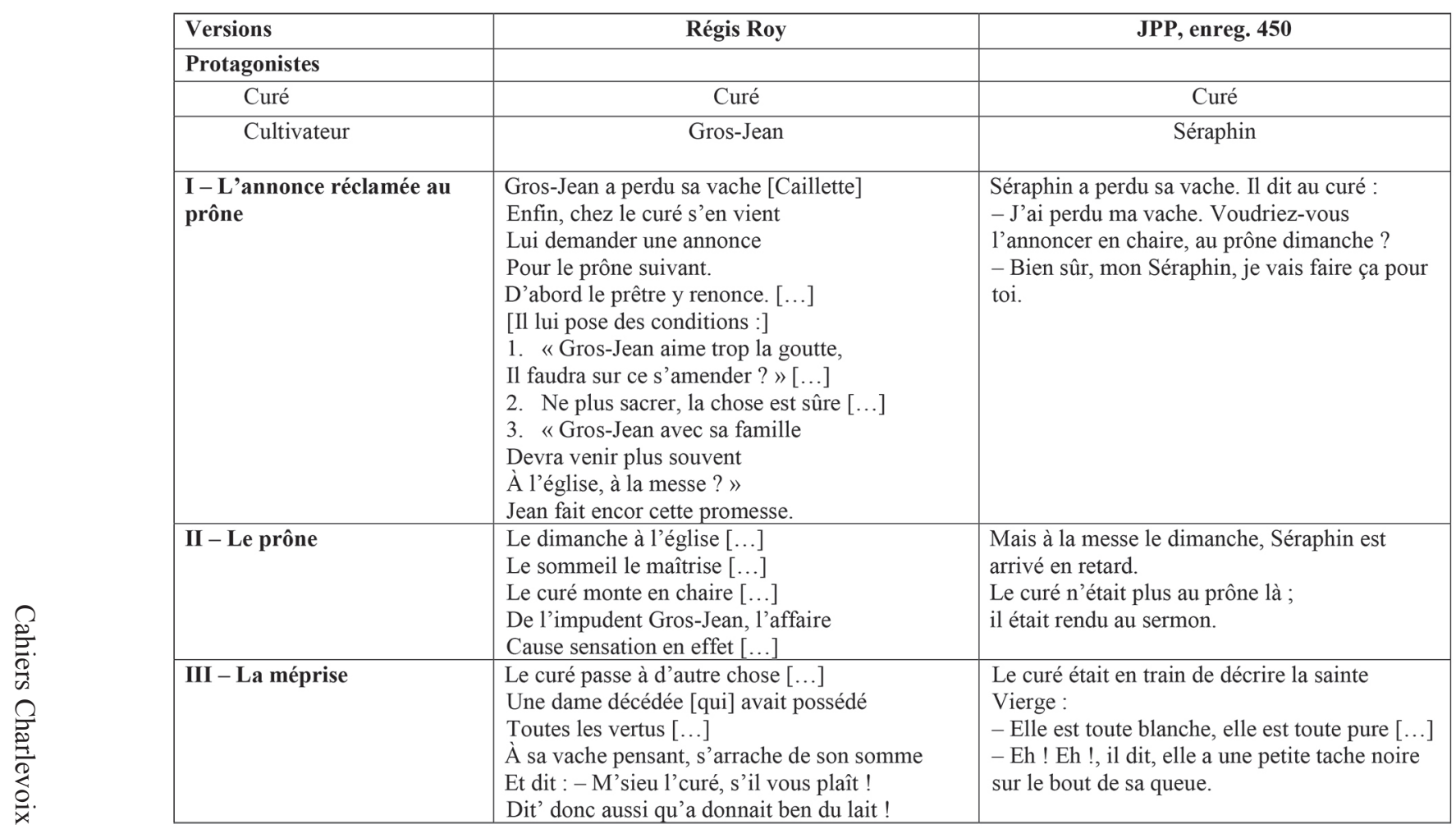


quand il recommande aux prières l'âme d'une dame disparue en détaillant ses vertus. Croyant qu'il est question de sa vache, il s'empresse d'ajouter : «Dites donc qu'elle donnait bien du lait ! »

Le catalogue international ATU n'a pas créé un type particulier pour cette histoire. Néanmoins, elle correspond à la description du type 1831A* Actions inappropriées dans l'église ${ }^{48}$, un fourretout qui regroupe quelques orphelines du cycle ATU 1725-1849 Blagues sur les ecclésiastiques et les personnalités religieuses. La version orale qui suit offre de grandes similitudes avec celle de Régis Roy.

La vache à Séraphin : la tache noire sur le bout de la queue Bon, c'est encore mon Séraphin qui avait encore ${ }^{49}$ perdu sa vache. Ça fait que là, il va voir son curé. Il dit au curé, il dit :

- J'ai perdu ma vache. Voudriez-vous l'annoncer en chaire, au prône dimanche?

Ça fait que le curé dit :

- Bien sûr, mon Séraphin, je vais faire ça pour toi.

Mais à la messe le dimanche, Séraphin est arrivé en retard. Puis là, le curé [n']était plus au prône là ; il venait de passer, il était rendu au sermon. Puis ç'adonné que c'était un dimanche où est-ce qu'il parlait de la sainte Vierge. Ça fait que, là, le curé était en train de décrire la sainte Vierge :

- Elle est toute blanche, elle est toute pure, elle a un regard d'azur, elle a de beaux yeux...

Ça fait que là, mon Séraphin, voyant que le curé continuait tout droit, il dit :

- Eh! Eh !, il dit, elle a une petite tache noire sur le bout de sa queue. ${ }^{50}$

48. Suggestion de Josiane Bru.

49. Cette histoire survient après la narration, par le même, d'une autre version de «La Vache à Séraphin : as-tu vu ma vache ? », une variante du type AтU 1355B " Je peux voir tout l'univers » : collection Jean-Pierre Pichette, enreg. 449 : elle met en scène le même personnage qui a perdu sa vache, mais se déroule dans un contexte différent.

50. Collection Jean-Pierre Pichette, enreg. 450, version de Jean-Pierre Pichette, enregistrée à Notre-Dame-des-Laurentides, Québec, le 11 juin 1977. 
En consultant le tableau synoptique, on aura noté les mêmes traits dans les deux versions après la situation de départ, la disparition de la vache du héros : la demande faite au curé d'en faire l'annonce à l'église, l'absence temporaire du protagoniste au moment du prône, causée par le sommeil ou un retard, et la méprise finale quand le héros présume que le prêtre signale les caractéristiques de son animal alors qu'il vante les mérites d'une dame vertueuse ou de la sainte Vierge. Toutefois, cette version n'a pas retenu la négociation moralisatrice du curé qui conditionne l'annonce à un changement de comportement du héros, mais accueille sans ambages la demande de son paroissien comme si elle allait de soi.

5. «ET BONAE VOLUNTATIS $»^{51}$

Dans la campagne où demeurait Gros-Jean,

Les habitants n'avaient pour temple

Qu'un édifice humble, uni, par exemple,

Comme leur foi, mais rien de plus touchant.

L'on n'y disait d'abord que messe basse, 5

Pas de pompe, éclat ni chant,

Car personne n'était de classe

À distinguer le do du ré.

Mais bientôt la nouvelle passe

Au prône du curé

Qu'en visite pastorale

Monseigneur va venir. On dira ce qu'on voudra

Mais ce que cela revira

Les habitants, et coetera [sic],

Pour telle fête capitale,

On n'en a pas le plus léger soupçon :

Nettoyer proprement la place principale,

Décorer chacun sa maison,

Dresser devant le presbytère

Un arc verdoyant

En l'honneur du haut dignitaire ;

Le temple du Saint-Mystère

Aura nouvel air festoyant

Sous son odorante parure

51. Régis Roy, L'Épluchette, op. cit., 1916, p. 63-65. 
De rameaux, fleurs et verdure.

Puis, monsieur le curé

A préparé

Une adresse de bienvenue.

L'institutrice est venue

Ensuite suggérer

D'avoir une messe chantée,

Ne fut-ce qu'en pl[a]in-chant.

La chose bien représentée

Passa sur le champ.

On embaucha pour cette circonstance,

Gros-Jean et son ami le maréchal-ferrant ;

Les deux plus belles voix de n'importe quel « rang ».

On leur apprit stance par stance

Alternativement

Pour aller plus rapidement.

Gros-Jean avait un appendice

Nasal un peu fort ;

L'autre tirait d'un orifice

Buccal énorme, une voix de stentor.

L'effet était bizarre ;

L'un nasillait,

L'autre tonitruait.

Mais la messe commence avec un entrain rare.

Tout va bien jusqu'au Gloria.

L'officiant préluda,

Puis le maréchal entonna.

Gros-Jean et lui tenaient le même livre.

Vulcain, aux mots :-Et bonae...

Regarde Gros-Jean qui doit suivre,

Et comme il a donné

Ce mot avec un sourire,

Gros-Jean y trouve à redire ;

Il y flaire une allusion

À son organe et dit avec dérision

Lui laissant la place seule :

- Chante tout seul, grosse gueule !

\section{Commentaires et comparaison}

Cette pièce de 61 vers irréguliers de 4 à 13 pieds, privilégiant des mètres de 8,7 et 6 pieds, étale en alternance et de façon aléatoire 
des séries de rimes embrassées, croisées et suivies. Un long préambule de 34 vers expose l'événement unique qui se déroulera dans une humble église rurale : la visite pastorale de l'ordinaire du lieu. Pour la circonstance, entre autres apprêts, on a retenu les « deux plus belles voix » des rangs avoisinants qui s'uniront pour chanter, « en l'honneur du haut dignitaire », une messe fastueuse, « ne fut-ce qu'en plain-chant ». Mais, dans cette campagne où personne ne sait « distinguer le do du ré », on leur apprend par cœur les stances en latin, la langue de l'église que n'entendent pas les « habitants ». On arrive alors à la scène principale. Les chantres sont défavorisés par la nature, Gros-Jean possédant « un appendice nasal un peu fort » qui le fait nasiller et son compagnon « un orifice buccal énorme » qui lui donne « une voix de stentor». On conçoit dès lors que chacun des « amis » est conscient de la situation et que la moindre allusion au défaut de l'autre risque de compromettre la bonne entente. Or, la prestation des chantres se passe normalement jusqu'au moment où, par inadvertance ou délibérément on ne saurait dire, le maréchal à la voix de stentor sourit en chantant $«$ bonae $»^{52}$. Gros-Jean, qui a compris « beau nez » et détecté dans cette attitude une insinuation à sa difformité, réplique illico à son assaillant par une formule impitoyable : « Chante tout seul, grosse gueule!»

On distingue encore un motif courant dans la littérature orale que le catalogue international range selon le cas soit avec les histoires de sourds, sous le type Atu 1698 G Des mots mal compris produisent des résultats comiques, mais dans la version Roy les résultats sont plutôt tragiques, soit avec les histoires de bègues, sous le type Aтu 1702 Anecdotes sur les bègues. Voici deux versions parallèles de cette histoire dont le récit se passe entre deux personnes qui tentent de s'apprivoiser malgré leurs défauts respectifs.

52. On a l'impression que les deux solistes ont appris séparément leur partition et que, faute de répétition générale, ils ne savaient pas d'avance ce que l'autre allait chanter. 


\section{Grand cou et grandes oreilles}

C'était un homme qui avait un complexe. Son complexe était qu'il avait un grand cou. Et il était très gêné de sortir. Un jour, il décida d'aller veiller dans un bar. Il rencontra une femme qui avait de grandes oreilles. Ils dansèrent ensemble toute la soirée. Il l'invita au restaurant. Après le restaurant, il alla la conduire chez elle. Mais la femme avait des difficultés à parler et elle dit avant de sortir :

- Merci beau cccoup [beau cou].

- Ma maudite " grandes oreilles », sors de l'auto et fiche le camp d'ici $!^{53}$

On aura noté que la compagne éprouve aussi des difficultés d'élocution, ce qui justifierait peut-être une association avec les histoires de bègues. La seconde version propose cette finale plus assurée.

[Chacun étant conscient du complexe de l'autre, l'homme fait attention de ne jamais faire allusion au défaut de sa compagne et celle-ci fait de même. La soirée se déroule ainsi parfaitement.] À la fin, en remerciant son compagnon, la dame dit :

- C'était une soirée formidable, merci beaucoup [beau cou]. Piqué au vif, l'homme réplique aussitôt :

- Va chier, grandes oreilles ! ${ }^{54}$

Dans les versions orales, c'est bien la dame qui commet la gaffe et, dans les deux exemples, elle est tout à fait involontaire. Son compagnon est tellement frustré et ombrageux qu'il ne laisse rien passer et condamne même un simple remerciement poli qu'il soupçonne, par équivoque, de cacher une allusion à son défaut physique.

\section{6. À TELLE ENSEIGNE ${ }^{55}$}

Un étranger arrête chez Gros-Jean

53. Collection Jean-Pierre Pichette, ms. 2465, version de Lise Journeault, Charlesbourg, Québec, décembre 1978. Selon Yves Frenette, qui connaissait la version de Paul Naud, de Portneuf, racontée à Donnacona ou à Québec vers 1974-1975, la finale était la suivante : «Toi, je t'ai-tu parlé de tes grandes oreilles ? (20 novembre 2017).

54. Collection Jean-PierrePichette, ms.non numéroté, version de Réal Bonenfant, Lac-Saint-Charles, v. 2005.

55. Régis Roy, L'Épluchette, op. cit., 1916, p. 19. 
Tableau 5 - «Et bonae voluntatis » L'Épluchette, 1916 (p. 63-65)

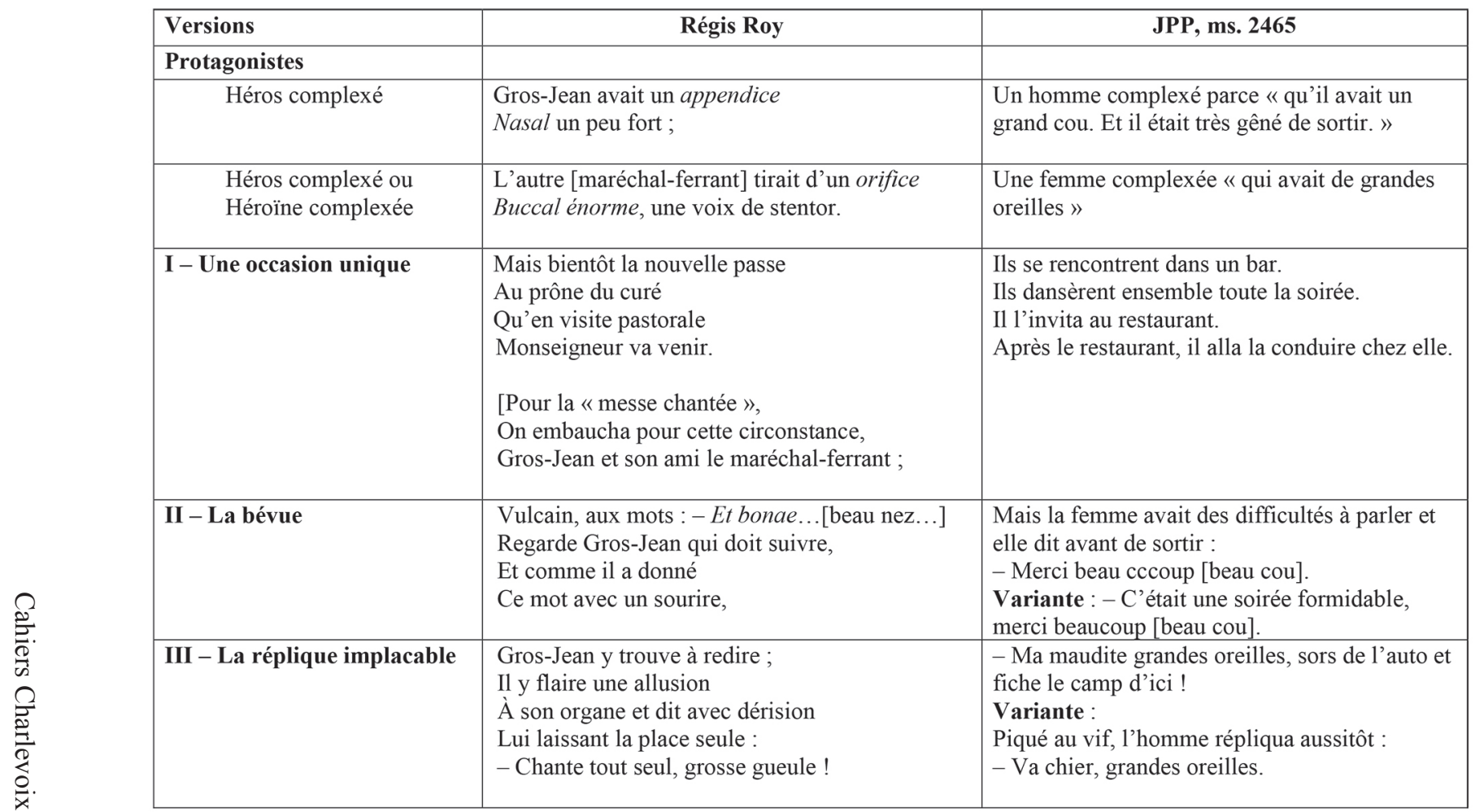


Et demande à voir le maître.

Fanfan se penche à la fenêtre

Et dit : - Il est au bout du champ

Là-bas, il travaille

Dans la soute aux g[o]rets.

Vous le reconnaîtrez sans frais ;

C'est lui qui porte un chapeau d'paille!

\section{Commentaires et comparaison}

La formule poétique de ce petit conte en vers est simplement composée d'une strophe de huit vers irréguliers, formée pour moitié d'octosyllabes et, pour le reste, de vers de cinq, six, sept et dix pieds, à rimes embrassées.

L'anecdote que l'auteur rapporte se fonde sur un quiproquo. Fanfan renseigne le visiteur et lui indique que son mari Gros-Jean, qui travaille dans la « soute aux gorets » [soue à cochons], est aisément reconnaissable au chapeau de paille qu'il porte. C'est l'ambiguïté de cette réponse qui fait sourire. On se demande qui est ici le plus simplet : l'épouse, candide ou retorse, qui laisse tomber que son mari est le seul « cochon » à porter un chapeau, commet-elle un lapsus ou porte-t-elle un jugement? Ne serait-ce pas plutôt l'étranger qui se révélerait incapable de distinguer le maître parmi les gorets de la soue ? La version orale qui suit se montre plus claire, car, au commerçant de moulée qui voudrait se faire présenter au mari, l'épouse délurée réplique qu'il reconnaîtra sans peine le cultivateur au chapeau de paille qu'il est le seul à porter dans la soue.

\section{Celui qui a un chapeau}

C'était un cultivateur qui avait une grosse porcherie. Et puis, vous savez, quand il y a un cultivateur qui a une grosse porcherie comme ça, il lui arrive des voyageurs de moulée assez souvent. Ça fait qu'il arrive un voyageur puis il demande à sa femme :

- [Combien] vous voulez que je vous vende de moulée : cinq cents poches?

Toujours, elle dit :

- Je signe rien. Allez le [mon mari] trouver là, il est dans la porcherie. Il arrangera ça comme il voudra. 
Tableau 6 - « À telle enseigne » L'Épluchette, 1916 (p. 19)

\begin{tabular}{|c|c|c|}
\hline Versions & Régis Roy & JPP, enreg. 1527 \\
\hline Protagonistes & & \\
\hline Visiteur & Un étranger arrête chez Gros-Jean & $\begin{array}{l}\text { Commerçant [commis-voyageur] de moulée à } \\
\text { cochon }\end{array}$ \\
\hline $\begin{array}{l}\text { Épouse d'un éleveur de } \\
\text { porcs }\end{array}$ & Fanfan & $\begin{array}{l}\text { La femme du cultivateur " qui avait une grosse } \\
\text { porcherie » }\end{array}$ \\
\hline I - Le patron recherché & Et [l'étranger] demande à voir le maître. & $\begin{array}{l}\text { - Combien de poches de moulée ? } \\
\text { - Je ne signe rien. Allez trouver mon mari... }\end{array}$ \\
\hline II - Où est-il ? & $\begin{array}{l}\text { - Il est au bout du champ } \\
\text { Là -bas, il travaille } \\
\text { Dans la soute aux gôrets. }\end{array}$ & - Il est dans la porcherie. \\
\hline $\begin{array}{l}\text { III - Comment le } \\
\text { reconnaître? }\end{array}$ & $\begin{array}{l}\text { Vous le reconnaîtrez sans frais } \\
\text { C'est lui qui porte un chapeau d'paille }\end{array}$ & $\begin{array}{l}\text { - Vous pourriez pas venir me l'introduire? } \\
\text { - Vous aurez pas de misère à le reconnaître. } \\
\text { Il y a seulement lui qui a un chapeau de paille. }\end{array}$ \\
\hline
\end{tabular}


- Vous pourriez pas venir me l'introduire?

- Ah, elle dit, prenez la porte du bout là. Vous aurez pas de misère à le reconnaître. Il y a seulement lui qui a un chapeau de paille. ${ }^{56}$

Cette petite histoire n'apparaît pas telle quelle au catalogue international, mais elle pourrait figurer parmi les Histoires sur les couples mariés (Atu 1350-1439).

\section{TOUT SON TEMPS ${ }^{57}$}

Madame Gros-Jean n'était plus :

Partie au séjour des élus

Depuis bientôt une semaine !

Gros-Jean avait beaucoup de peine.

Or, il rencontre le curé,

Sur le chemin de blanc poudré ;

On se salue et l'on s'arrête.

Sur la perte qu'il avait faite

Le curé console Gros-Jean,

Une par une énumérant

Les qualités de la pauvre âme.

C'était une bien bonne femme!

Et Gros-Jean acquiesce en tout.

Puis, changeant de ton, tout à coup,

Le digne prêtre alors ajoute :

- Elle était bien bonne, sans doute,

Et sauvée aussi, je le crois,

Mais bien peu vont au ciel tout droit.

Aurait-elle eu ce privilège

Pour lequel faut blanc comme neige?

Hum ! il est permis d'en douter.

On peut penser sans hésiter

Qu'elle doit être au purgatoire.

Un lieu, vous savez, qu'est notoire

Pour être rempli de tourments ;

Où des âmes souffrent longtemps.

Il vous faudrait prier sans cesse,

Faire souvent dire la messe

56. Collection Jean-Pierre Pichette, enreg. 1527, version de M. Joseph-Philippe Bouffard, enregistrée le 5 août 1980 à Saint-Léon-de-Standon, Québec.

57. Régis Roy, L'Épluchette, op. cit., 1916, p. 132-133. 
Afin de raccourcir son temps...

- Vous ne connaissez pas ma vieille,

La défunte a pas sa pareille :

Elle aurait dix, vingt, ou trente ans,

Dit Jean, mais elle est ordilleuse

Et si tellement scrupuleuse

Qu'a voudra faire tout son temps!

\section{Commentaires et comparaison}

Formellement, le poème de Régis Roy se compose de 35 vers isométriques de huit pieds, bien réguliers, à rimes ou assonances suivies deux à deux (v. 1-28) puis, en finale, à rimes embrassées (v. 29-35) ; le vers 32, qui compterait double, sert d'articulation entre les deux quatrains (v. 29-32 et 32-35). Le récit se divise en trois parties. Dans un premier temps, après une brève introduction (v. 1-4), Gros-Jean, veuf depuis moins d'une semaine, rencontre son curé, qui le console en vantant les mérites de la défunte (v. 5-13). Puis, en dépit des vertus incontestables de l'épouse, le pasteur « change de ton » et rappelle qu'elle devra séjourner au purgatoire dans la souffrance, car peu vont directement au ciel ; il suggère alors à Gros-Jean de prier beaucoup et de « faire souvent dire la messe » pour abréger ses tourments (v. 14-29). Mais le mari l'a vu venir et sa réponse ne tarde pas : son épouse est si orgueilleuse et si scrupuleuse qu'elle « voudra faire tout son temps » (v. 30-35).

Après la mort d'un parent, la coutume catholique veut qu'on offre des messes pour le repos de l'âme du défunt en plus des funérailles. Ces messes sont célébrées dans les semaines ou les mois qui suivent le décès, puis le jour de son premier anniversaire qui réunit la famille et les proches du défunt; par la suite, d'autres messes peuvent être célébrées selon la piété des endeuillés. Bien que l'Église interdise la vénalité de tels services spirituels, elle suggère à la famille une participation aux frais sous forme d'offrande dont le tarif est fixé par le diocèse. Aussi, dans l'usage populaire, désigne-t-on encore cette offrande par des expressions comme « faire dire ou chanter une messe », mais plus couramment « acheter une messe » ou « payer une messe » pour un défunt. 
Autrefois, cet acte religieux étant tarifé, des familles peu fortunées devaient parfois se limiter aux offrandes recueillies lors de la « quête au service », c'est-à-dire la collecte faite lors de la messe des funérailles qui pouvait être partiellement affectée à cette fin, et à la messe anniversaire.

À n'en pas douter, ce récit a des parallèles dans la tradition orale du Canada français. Bien que le catalogue international ne lui ait pas attribué de cote spéciale, il pourrait s'insérer dans l'un ou l'autre des cycles ATU 1350-1439 Histoires sur les couples mariés, ou AтU 1725-1849 Blagues sur les ecclésiastiques et les personnalités religieuses. Notre collection comprend deux versions de cette histoire qui proviennent de la même informatrice, $M^{\text {me }}$ Noëlla Saint-Hilaire (née en 1919). Les voici.

[Une femme qui paie des messes pour que son mari aille au ciel]

Un jour, il y avait une femme que son [dont le] mari était décédé. Puis, comme toutes les bonnes mamans, elle voulait bien que son mari alle [aille] au ciel. Mais, elle était pas très, très riche. Tout de même, monsieur le curé trouvait qu'elle payait pas de messes souvent. Une bonne fois, elle se décide, elle s'en va au presbytère puis elle dit à monsieur le curé :

- Pensez-vous que mon mari est sauvé ?

- Ah ! il dit, ça lui prendrait bien quelques messes.

Ça fait qu'elle prend de l'argent puis elle le met sur le bureau de monsieur le curé. Puis, elle dit :

- Là, pensez-vous qu'il est au ciel ? Il dit :

- Non, mais il est dans le bon chemin.

Alors, elle prend un autre vingt-cinq piastres puis elle [le] met sur le bureau du curé. Puis elle dit:

- Là, pensez-vous qu'il est sauvé ?

- Bien là, il dit, il est rentré dans le ciel.

- Ah ! bien, elle dit, à cette heure qu'il est rentré - elle ramasse l'argent, elle [le] met dans ses poches -, à cette heure qu'il est rentré, têtu comme je le connais, il ressortira pas. ${ }^{58}$

58. Collection Jean-Pierre Pichette, enreg. 1263, version de $\mathrm{M}^{\mathrm{me}}$ Noëlla SaintHilaire (M ${ }^{\text {me }}$ Émile Guay), Saint-Léon-de-Standon, Québec, recueillie le 2 août 1979. 
Tableau 7 - « Tout son temps » L'Épluchette, 1916 (p. 132-133)

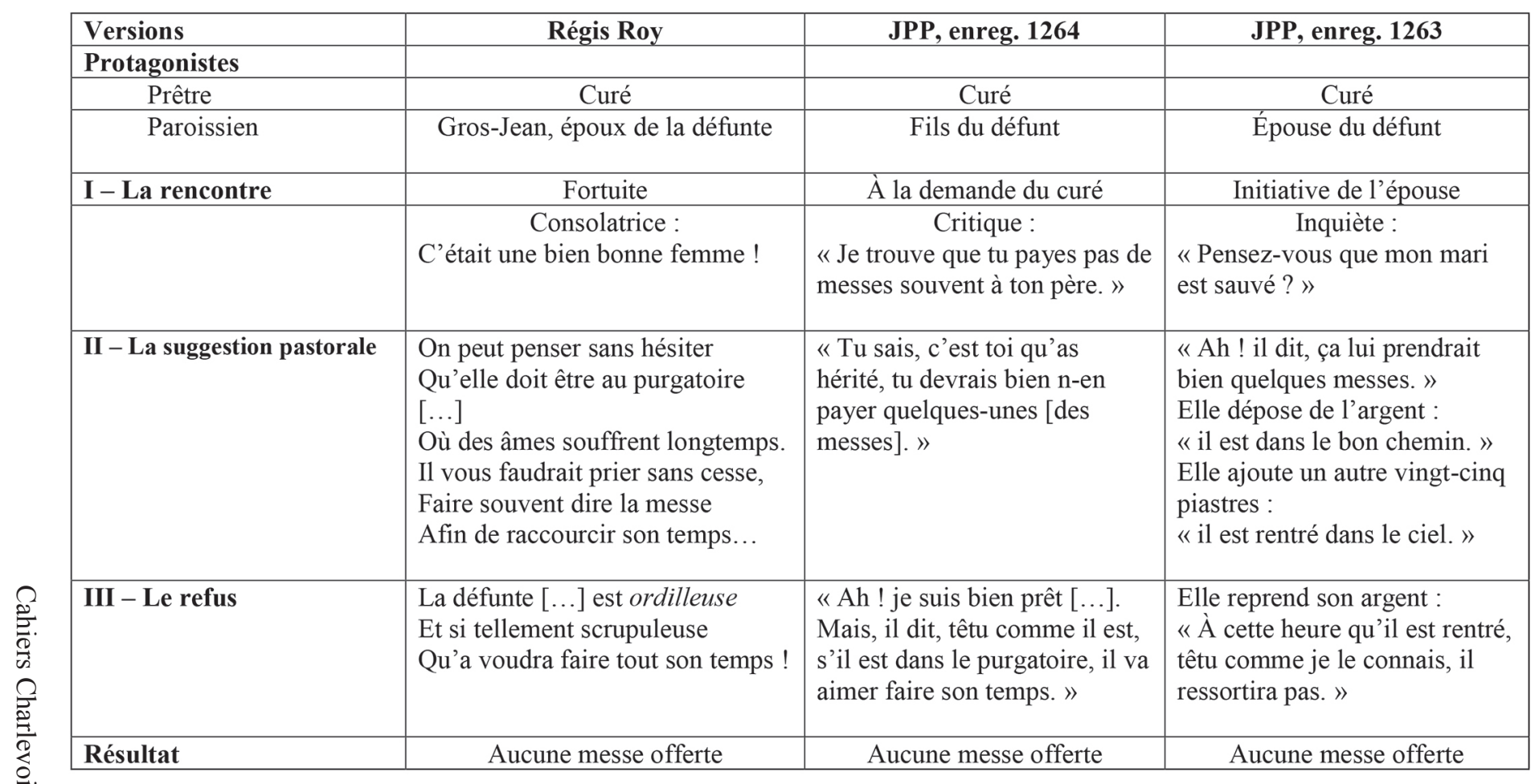


Cette première version orale pourrait trouver sa place parmi les multiples variations du type ATU 1365 L'Épouse obstinée qui compte aussi des exemples où l'obstiné est un homme. Ici, la veuve, habile à négocier une place au ciel pour son mari, rappelle les tours facétieux de Ti-Jean joueur de tours.

[Un fils qui ne veut pas payer de messe pour son père]

C'était un type comme ça qu'était décédé, et puis c'était son garçon qui avait hérité. Et puis, monsieur le curé, comme ça, il trouvait qu'il payait pas de messes souvent. Ça fait qu'il s'en va trouver le curé, il dit :

- Coudon [Écoute donc], vous m'avez fait demander? Il dit :

- Oui, je trouve que tu payes pas de messes souvent à ton père. Il dit: Tu sais, c'est toi qu'as hérité, tu devrais bien n-en payer quelques-unes.

- Ah ! il dit, je suis bien prêt à n-en payer quelques-unes. Mais, il dit, têtu comme il est, s'il est dans le purgatoire, il va aimer faire son temps. ${ }^{59}$

Ce second récit est à rapprocher du motif M256.1 du Motif-Index of Folk Literature de Stith Thompson, dont le résumé se lit ainsi : «Les fils rompent la promesse d'offrir des messes pour l'âme de leur père. "S'il est en enfer, ça ne lui fera aucun bien ; s'il est au ciel, il n'en aura pas besoin ; et s'il est au purgatoire, il peut lui-même purger sa peine". ${ }^{60}$ » On peut le mettre en rapport avec les variations du type ATU 1804 Une pénitence imaginée pour un péché imaginaire dans lesquelles le prêtre échoue dans son entreprise de soutirer de l'argent en retour de l'administration d'un sacrement, la confession surtout.

Le discours populaire, qui s'exprime ici par un conte facétieux, caricature les personnages. Le prêtre, par dérision et subversion, devient un être cupide, plus comptable que pasteur, qui cherche son profit. Il s'oppose à un mari endeuillé, pauvre peut-être, rusé

59. Collection Jean-Pierre Pichette, enreg. 1264, version de $\mathrm{M}^{\text {me }}$ Noëlla SaintHilaire (M ${ }^{\text {me }}$ Émile Guay), Saint-Léon-de-Standon, Québec, recueillie le 2 août 1979.

60. Traduction de l'auteur: Motif M256.1. Sons break promise to have masses for father's soul. "If he is in hell it will do him no good; if he is in Heaven he won't need it ; and if he is in Purgatory he can purge himself $»$ Italian Novella : Rotunda. 
ou faussement naïf, une veuve inquiète du sort de son mari, ou un fils, qui ne peut ou ne veut pas « payer de messe » pour son épouse, son mari, son père. Dans cette joute, comme toujours dans les contes populaires, c'est le personnage le plus malin qui triomphe, et non le plus fort, le plus riche, le plus savant.

Le tableau synoptique qui suit reprend les divers éléments de comparaison entre la version Roy et celles de notre informatrice.

8. OCTAVe de NoËL $(1906)^{61}$ [1 $1^{\text {ère }}$ version]

C'était dans le temps de Noël.

Jean Rustaud s'en vint à l'église

Pour prier le petit Noël.

Le bonhomme à tête grise,

Terminant ses dévotions :

Chemins de croix, puis oraisons,

Deci, delà, par les allées,

Le voilà qui passe et revient.

Le curé voyant ces allées

Se dit : - «Il cherche, sûr, quelque chose », et dit bien. 10

$\mathrm{Au}$ vieillard qui passe et repasse,

Il demande enfin : - « Cherchez-vous

L'Enfant-Jésus ? - Non, m'sieur l'curé, du tout :

Je cherch' l'enfant d'Chine qu'a pris mon casse !! »

OCtave de NoËL $(1928)^{62}$ [2 $2^{\mathrm{e}}$ version]

C'était dans le temps de Noël.

Lorsqu'un jour, le vieux Michel

Bonhomme à la tête grise,

Alla faire un tour à l'église

Terminant ses dévotions :

Chemins de croix, puis oraisons.

Deci, delà, par les allées,

Le voilà qui passe et revient.

Le curé voyant ces allées,

Se dit :- Que cherche-t-il bien ?

$\mathrm{Au}$ vieillard qui se promène

Et semble en peine

Et dont la vue est en défaut,

61. Régis Roy, Les Joyeux Petits Contes canadiens, op. cit., 1906, p. 70.

62. Régis Roy, Les Joyeux Propos de Gros-Jean, op. cit., 1928, p. 47-48. 
Il demande : - Voyons, père !

Qu'y a-t-il ? Ça va bien, j'espère ?

- Oui !... oui !... - Avez-vous vu

Notre petit Enfant Jésus?

(Le vieux se gratte la nuque.)

- C'est pas ça, m'sieur l'curé,

J'voudrais voir l'enfant sucré

Qui m'a volé ma tuque !

\section{Commentaires et comparaison}

La première version de 1906 comprenait quatorze vers, essentiellement octosyllabiques (sauf l'heptasyllabe du v. 4, le dodécasyllabe du v. 10 et les décasyllabes des vers 13-14), à rimes variées : d'abord croisées (v. 1-4), puis suivies (v. 5-6), de nouveau croisées (v. 7-10) et finalement embrassées (v. 11-14). On s'attendrait pour la seconde version, celle de 1928, à une régularisation de la structure poétique. Beaucoup s'en faut. Bien qu'il ait réaménagé son récit, en l'allongeant à vingt et un vers, et fait un effort pour les raccourcir en octosyllabes, il ne parvient pas à une juste mesure : sept vers n'ont que sept syllabes, trois en ont six, un en a quatre. Quant à l'alternance des rimes, elles sont suivies (v. 1- 6), croisées (v. 7-10), suivies encore (v. 11-12), et, après un vers blanc (v. 13), de nouveau suivies (v. 14-17) et embrassées (v. 18-21). Considérant la mesure des vers, l'agencement et la qualité des rimes, qui oscillent entre pauvres et suffisantes, la forme poétique de ce fabliau laisse nettement à désirer.

Mais c'est le contenu populaire qui doit retenir l'attention. Peu de modifications à ce chapitre entre les deux versions de l'auteur. On constate que le nom de Jean Rustaud a été remplacé par le vieux Michel, mais les protagonistes restent les mêmes, le moment et le lieu aussi. La différence la plus remarquable réside dans la conclusion. Là où Willy de Grécourt pouvait écrire « Je cherch' l'enfant d'Chine qu'a pris mon casse [casque pour chapeau] !! », Régis Roy, reprenant sa facétie sous son nom véritable, doit « épluchette faire » et atténuer la colère et la verdeur du langage de son personnage : « J' voudrais voir l'enfant sucré 
Tableau 8 - « Octave de Noël »

\begin{tabular}{|c|c|c|c|}
\hline Versions & Willy de Grécourt & Régis Roy & JPP, ms. 46 \\
\hline Protagonistes & & & \\
\hline Prêtre & Curé & Curé & Prêtre \\
\hline Paroissien & Jean Rustaud & Le vieux Michel & Un pénitent \\
\hline I - L'occasion & Temps de Noël & Temps de Noël & À la confesse \\
\hline & $\begin{array}{l}\text { Jean Rustaud s'en vint à l'église } \\
\text { Pour prier le petit Noël. [...] } \\
\text { Terminant ses dévotions : } \\
\text { Chemins de croix, puis oraisons, } \\
\text { Deci, delà, par les allées, } \\
\text { Le voilà qui passe et revient. }\end{array}$ & $\begin{array}{l}\text { Lorsqu'un jour, le vieux Michel } \\
{[\ldots]} \\
\text { Alla faire un tour à l'église } \\
\text { Terminant ses dévotions : } \\
\text { Chemins de croix, puis oraisons. } \\
\text { Deci, delà, par les allées, } \\
\text { Le voilà qui passe et revient. }\end{array}$ & $\begin{array}{l}\text { Au sortir du confessionnal, un } \\
\text { homme faisait mine de } \\
\text { chercher quelque chose. }\end{array}$ \\
\hline II - La question & $\begin{array}{l}\text { Le curé voyant ces allées }[\ldots] \\
\text { Au vieillard qui passe et repasse, } \\
\text { Il demande enfin : - "Cherchez-vous } \\
\text { L'Enfant-Jésus? }\end{array}$ & $\begin{array}{l}\text { Le curé voyant ces allées }[. . .] \\
\text { Au vieillard qui se promène } \\
\text { Et semble en peine }[. . .] \\
\text { Il demande }: \text { - Voyons, père ! } \\
\text { Qu'y a-t-il ? Ça va bien, j'espère ? } \\
\text { - Oui !... oui !... - Avez-vous vu } \\
\text { Notre petit Enfant Jésus ? }\end{array}$ & $\begin{array}{l}\text { Voulant aider ce brave } \\
\text { paroissien, le prêtre lui } \\
\text { demande : «Cherchez-vous } \\
\text { l'enfant Jésus? » }\end{array}$ \\
\hline III - La réplique & $\begin{array}{l}\text { - Non, m'sieur l'curé, du tout: } \\
\text { Je cherch' l'enfant d'Chine qu'a pris } \\
\text { mon casse !! }\end{array}$ & $\begin{array}{l}\text { - C'est pas ça, m'sieur l'curé, } \\
\text { J' voudrais voir l'enfant sucré } \\
\text { Qui m'a volé ma tuque! }\end{array}$ & $\begin{array}{l}\text { "-Non, je cherche l'enfant de } \\
\text { chienne qui a pris mes } \\
\text { claques!» }\end{array}$ \\
\hline
\end{tabular}


/ Qui m'a volé ma tuque! » La version que nous avons recueillie est encore plus crue.

\section{Le pénitent et ses claques}

Au sortir du confessionnal, un homme faisait mine de chercher quelque chose. Voulant aider ce brave paroissien, le prêtre lui demande : «Cherchez-vous l'enfant Jésus ? - Non, je cherche l'enfant de chienne qui a pris mes claques! $!{ }^{63}$

Le rire est ici provoqué par le contraste entre le désir du prêtre, soucieux de venir en aide à son paroissien, qui lui demande candidement s'il cherche l'enfant Jésus, ce qui serait normal dans une église, plus encore dans le temps de Noël où on monte une crèche qui expose la scène de la nativité, et l'irritation du paroissien qui tente vainement depuis un bon moment de retrouver un objet perdu. Aussi, la question obligeante du prêtre provoquet-elle l'exaspération du paroissien qui saisit le mot enfant pour qualifier le voleur, ou le distrait le privant de son vêtement, et qui explose en invectives qui n'ont pas leur place à l'église : enfant sucré, enfant de Chine ou enfant de chienne. L'histoire ne dit pas l'ahurissement du prêtre devant cette exclamation surprise, mais le laisse supposer.

Comme le fabliau précédent, ce quiproquo mettant en scène un prêtre et un fidèle relève du cycle international ATU 17251849 réservé aux blagues sur les pasteurs et les personnalités religieuses, sans qu'il soit possible de lui attribuer un numéro particulier tant elles sont nombreuses.

\section{B. La veine populaire avérée}

Notre démonstration s'arrête ici. L'examen des huit contes choisis, que nous avons juxtaposés et comparés à des versions parallèles puisées dans la tradition orale du Canada français autant que dans le folklore international, répond à satiété à la question qui a orienté cette étude : les «contes amusants » qui ont inspiré la poésie de divertissement de Régis Roy proviennent-ils « du terroir », tel

63. Collection Jean-Pierre Pichette, ms. 46, notée à Québec avant 1973. Publiée dans Le Guide raisonné des jurons, op. cit., p. 70. Yves Frenette commente : « Je l'ai entendue plusieurs fois à Cap-Santé, entre 1967 et 1972 »(20 novembre 2017). 
qu'il l'a spontanément avancé dans la préface de son premier recueil ? Il ne fait plus aucun doute que cette affirmation est avérée et que les récits que l'auteur a transposés en vers circulaient dans les milieux populaires de son temps comme ils continuent de le faire de nos jours. En dépit de la versification maladroite dont il a enveloppé ces « contes joyeux », son intervention a néanmoins pérennisé des paroles éphémères bien avant l'ère des premiers folkloristes-ethnologues ; d'ailleurs, les Barbeau, Lacourcière, Lemieux s'attacheraient d'abord, par leur attention soutenue, au sauvetage du conte merveilleux, davantage menacé que ces innombrables et souvent banales petites histoires ${ }^{64}$.

L'édition en 1906 des Joyeux Petits Contes canadiens, première compilation de courtes histoires « du terroir », inaugurait une plaisante trilogie d'inspiration populaire. Ce faisant, Régis Roy, sans le savoir peut-être, se greffait aux collecteurs des vieux mots et des vieilles choses assemblés autour des fondateurs du Bulletin du parler français au Canada, créé en 1902, en vue de produire un glossaire franco-canadien. Son œuvre précédait même le mouvement régionaliste qu' allait animer Adjutor Rivard à partir de 1914 avec les religieux Camille Roy, Lionel Groulx, MarieVictorin, le frère Gilles, et des laïcs aussi, Georges-Émile Marquis, Blanche Lamontagne-Beauregard et Georges Bouchard ${ }^{65}$. Grâce à ses petits recueils, Régis Roy devenait le premier en Ontario à noter des contes facétieux de tradition orale de son milieu et le seul à les avoir remodelés en véritables fabliaux puisqu'il les présentait sous une forme versifiée. À ce titre, il s'était taillé une place originale dans la littérature franco-ontarienne.

64. Un dépouillement systématique des périodiques d'agrément, tels Le Canard, Le Passe-Temps et plusieurs autres, tant anciens que contemporains, révélerait bien d'autres traces de l'empreinte profonde de la tradition orale sur la culture populaire.

65. Marie-Andrée Beaudet, « Chez nous d'Adjutor Rivard : esthétique et fortune littéraire », dans Tangence, $\mathrm{n}^{\circ}$ 40, "Régionalismes littéraires de la francophonie ", mai 1993, p. 28-38 ; Aurélien Boivin, «L'Apport des religieux dans la propagation des récits régionalistes ", dans Port-Acadie, $\mathrm{n}^{\text {os }}$ 24-25-26, "L'Apport des prêtres et des religieux au patrimoine des minorités », 2013-2014, p. 212-225. 
Conclusion

\section{A. Un poète oublié ?}

Dans son Anthologie de la poésie franco-ontarienne : des origines à nos jours ${ }^{66}$, René Dionne n'a retenu aucun poème des trois recueils de Régis Roy. De prime abord, au regard des critères que l'anthologiste a établis, cette omission paraît déconcertante, notamment par sa qualité d'auteur franco-ontarien et la notion d'œuvre poétique.

Pourtant, cet écrivain répondait entièrement au tout premier critère, soit « des œuvres écrites en français par des auteurs qui sont nés en Ontario » : né en 1864 à Ottawa, ville où il a étudié, travaillé toute sa vie, écrit en français et dont il a fréquenté les milieux littéraires, mais aussi populaires, Régis Roy aligne un profil indiscutable, voire exemplaire, d'auteur franco-ontarien; on le considère même « comme le premier écrivain franco-ontarien né en Ontario ${ }^{67} \gg$. Bien plus, ses livres se conforment aisément à chacun des autres volets définissant la spécificité « francoontarienne » : des auteurs « qui habitent cette province, ou qui ont écrit la plupart de leurs ouvrages pendant qu'ils y résidaient, ainsi que les œuvres de langue française dont l'Ontario est le cadre ou le sujet. ${ }^{68}$ » En réalité, Régis Roy satisfait toujours à chacun et, parfois, à tous ces articles en même temps.

Mais, s'agissant d'une anthologie, un assemblage de morceaux choisis ou florilège, et non d'un dictionnaire ou d'une encyclopédie, d'autres modalités, subjectives celles-là, s'appliquaient aussi : «d'abord des auteurs qui représentaient bien une époque par leurs thèmes et la qualité de leur écriture ou se distinguaient par leur originalité. En principe, ces auteurs devaient avoir publié au moins deux recueils de poèmes. » Dans la pratique, Dionne concède avoir, ici et là, dérogé à ces paramètres. Par exemple,

66. René Dionne, Anthologie de la poésie franco-ontarienne : des origines à nos jours, Sudbury, Prise de parole, 1991, 223 p.

67. Jean-Yves Pelletier, « Régis Roy, 15 février 2015 », notice biographique publiée pour le $400^{\mathrm{e}}$ anniversaire de l'Ontario. Source : ontario400.ca/400jours/regisroy, consultée le 19 avril 2017.

68. René Dionne, op. cit., p. 11. 
il est loin d'être assuré que le tout premier poème de l'anthologie, « la Complainte de Cadieux (vers 1709) », soit d'un auteur franco-ontarien ; rédaction anonyme d'une légende chantée, elle provient du recueil Forestiers et voyageurs de Joseph-Charles Taché (1820-1894), un auteur québécois devenu fonctionnaire à Ottawa ${ }^{69}$. Encore, des auteurs retenus n'ont parfois publié qu'un seul recueil, jugé « original ou prometteur » ${ }^{70}$.

L'intention de tirer de l'oubli un texte ancien ou de mettre en lumière des poètes méconnus, qui justifiait ces singulières exceptions, aurait-elle pu commander d'accorder aussi une petite place aux contes en vers de Régis Roy parmi la production clairsemée de ses contemporains ? L'originalité de sa poésie " joyeuse » jointe au petit nombre de poètes du début du vingtième siècle auraient naturellement autorisé ce choix. Se pourrait-il plutôt que l'anthologiste l'ait écarté à cause de la dimension narrative de sa «prose rimée »? Dans l'intitulé de ses recueils, l'auteur ne qualifie-t-il pas lui-même ses poèmes de « contes », de « propos » et de « monologues » ? Ainsi, René Dionne aurait réduit ces œuvres au genre conte, associant de ce fait son auteur aux écrivains qui transposaient à l'écrit des récits populaires, comme le firent Marie-Rose Turcot ou même des folkloristes-ethnologues, tels Marius Barbeau et Germain Lemieux, dans des adaptations pour la jeunesse ${ }^{71}$. Cette hypothèse demeure vraisemblable, car

69. Conrad Laforte, « La Complainte de Cadieux », Dictionnaire des æeuvres littéraires du Québec, Montréal, Éditions Fides, tome I Des origines à 1900, [1978], p. 133-134 : « Ce n'est qu'en 1863 que la chanson est imprimée par deux écrivains de Québec, Hubert Larue et Joseph-Charles Taché. En 1865, Ernest Gagnon en publie deux mélodies, empruntant le texte de la chanson et la légende à Taché. » (p. 134) Voir aussi l'étude de Marius Barbeau, « La Complainte de Cadieux, coureur de bois (ca. 1709) », Journal of American Folklore, vol. 67, n 254, avril-juin 1954, p. 163183 ; c'est le texte critique établi par Marius Barbeau que René Dionne a reproduit, op. cit., p. 17-19.

70. La bibliographie compilée par l'anthologiste compte 305 recueils, créés par 111 auteurs et collectifs dont 40 n'ont publié qu'un livre ; René Dionne a retenu les poèmes de cinq de ces derniers dans son anthologie : Alain Beauregard, Alfred Garneau, Gabrielle Poulin, Mariette Théberge et Michel Vallières.

71. Citons, par exemple, Marius Barbeau, Il était une fois..., Montréal, Éditions Beauchemin, [1935], 105 p. ; Marie-Rose Turcot, Au pays des géants et des fées, Ottawa, "Le Droit », [1936], 75 p. ; Germain Lemieux, Contes de mon pays, Montréal, Éditions Héritage, [1978], 159 p. Pour d'autres exemples franco-ontariens, 
René Dionne, chercheur rigoureux s'il en fût, n'aurait pas exclu cet auteur sans raison et négligé d'inscrire dans sa bibliographie les trois recueils de Régis Roy ${ }^{72}$. Dans l'avant-propos de son livre, Dionne prévenait le lecteur : « Il se peut que des ouvrages de poésie nous aient échappé, car il n'existe actuellement aucune bibliographie exhaustive des écrits franco-ontariens, et c'est de peine et de misère que nous avons établi au cours d'une quinzaine d'années la liste que nous publions. ${ }^{73}{ }^{\prime}$

\section{B. Dans un entre-deux littéraire}

La distinction classique entre prose et poésie, du moins au sens que lui donnent les dictionnaires, ne tiendrait plus. Le Robert définit encore la prose comme une «Forme du discours oral ou écrit, manière de s'exprimer qui n'est soumise à aucune des règles de la versification »; et la poésie comme un «Art du langage, visant

voir J.-P. Pichette, Répertoire ethnologique de l'Ontario français, Ottawa, Presses de l'Université d'Ottawa,1992, p. 116-123 : $\mathrm{n}^{\text {os }} 425-445$ (livres et brochures), 446-452 (périodiques illustrés) et 453-465 (bandes dessinées).

72. René Dionne, op. cit., p. 191-215 : aucun des titres de Régis Roy n’y apparaît. Rien non plus dans son Histoire de la littérature franco-ontarienne. Des origines à nos jours. Tome II, La littérature des fonctionnaires (1865-1910), Ottawa, Éditions du Vermillon, "Essais et recherches » 9, 2000, 355 p. ; ni dans son complément l'Anthologie de la littérature franco-ontarienne. Des origines à nos jours. Tome II, La littérature des fonctionnaires (1865-1910), Ottawa, Éditions du Vermillon, « Essais et recherches »10,2000, 380 p. ; normalement, si René Dionne avait voulu retenir l'œuvre de Régis Roy, c'est dans ces volumes qu'on la retrouverait. Par ailleurs, sa Bibliographie de la littérature outaouaise et franco-ontarienne, Ottawa, Centre de recherche en civilisation canadienne-française, "Documents de travail du CRCCF » 10, 1981, [4]-vii-204 p., présente 15 entrées, soit presque toute l'œuvre de Régis Roy, sous son nom. Il signale toutefois les trois recueils de Régis Roy parmi les « contes et nouvelles », p. 354-355, dans sa synthèse « La Littérature franco-ontarienne : esquisse historique (1610-1987) », dans Cornelius J. Jaenen, Les Franco-Ontariens, Ottawa, Presses de 1'Université d'Ottawa, 1993, p. 341-417. Sa dernière Bibliographie de la littérature franco-ontarienne 1610-1993, Ottawa, Éditions du Vermillon, « Essais et recherches » 8, 2000, 619 p., reprend la liste complète des écrits de Roy en 19 entrées (p. 539-541), mais elle comporte une surprenante anomalie : dans la liste chronologique des œuvres, deux des recueils de contes en vers apparaissent sous la subdivision «3.3 théâtre» (p. 118, 1916 L’Épluchette; p. 119, 1928 Joyeux Propos de Gros-Jean), ce qu'ils ne sont certainement pas, ou sous « 3.4 conte et nouvelle» (p. 123, 1906 Les Joyeux Petits Contes canadiens), ce qui s'explique plus facilement. Cette distraction du bibliographe manifeste l'insensibilité du chercheur envers une œuvre qu'il juge certainement mineure.

73. René Dionne, Anthologie de la poésie franco-ontarienne, op. cit., p. 12. 
à exprimer ou à suggérer par le rythme (surtout le vers), l'harmonie et l'image ». Le poème, qui reste un « Ouvrage de poésie en vers », se présente aussi comme «poème en prose, ne revêtant pas la forme versifiée ». Forme fixe, vers libre, etc., il semble que la versification ne suffise plus à distinguer la poésie de la prose et que l'on doive reléguer aux oubliettes la distinction que Molière faisait entendre par la voix du maître de philosophie : « tout ce qui n'est point prose est vers; et tout ce qui n'est point vers est $\operatorname{prose}^{74} \gg$. Auteur oublié, œuvre rangée dans une autre catégorie ou esthétique ne correspondant pas au dessein de l'anthologiste, on ne saurait déterminer avec certitude la raison de cette omission ${ }^{75}$. En écartant les trois recueils poétiques de Régis Roy, l'Anthologie de la poésie franco-ontarienne n'aura pas complètement rempli son projet de faire « goûter à de nombreux styles poétiques » et de tirer quelques poètes « d'un injuste oubli ». René Dionne assumait néanmoins sa sélection : «nous sommes le seul responsable du choix qui a été fait ${ }^{76} »$.

$\mathrm{Au}$ demeurant, ces remarques révèlent avant tout que ces petits contes en vers habitent un entre-deux où la poésie et le récit s'entremêlent.

\section{L'exemple des fabliaux}

Dans cet entre-deux littéraire logeaient déjà les fabliaux, un genre que Joseph Bédier remit à l'honneur à la fin du XIX ${ }^{\mathrm{e}}$ siècle. Dans l'introduction de sa thèse fondamentale, Les Fabliaux, il se défendait d'avoir choisi un sujet en apparence bien léger :

74. Molière, Le Bourgeois gentilhomme, acte II, scène VI.

75. Peu après la parution de son Anthologie de la poésie franco-ontarienne, nous avons signalé cette omission à René Dionne au hasard d'une conversation à Ottawa. Notre remarque l'étonna, comme s'il n'avait pas pensé à considérer les recueils de Régis Roy sous l'angle de la poésie, tant leur caractère de narration populaire lui paraissait dominant. Il est assuré qu'il connaissait très bien les trois livres en question puisqu'il avait préfacé notre Répertoire ethnologique de l'Ontario français, op. cit., qui, en plus de les décrire dans la section bibliographique, les présentait même en introduction parmi les travaux des préfolkloristes ayant produit des recueils de contes (p. 32-33).

76. René Dionne, op. cit., p. 12. 
Quelques-uns m'en feront reproche : les fabliaux étant les contes joyeux du moyen âge, à quoi bon alourdir ces amusettes par le plomb des commentaires érudits? Que nous importent, après tout, ces facéties surannées ? Ne suffisait-il pas de rire un instant de ces contes à rire, - et de passer ? / Pourtant j'ai traité gravement cette matière frivole. C'est à ces joyeusetés, voire à ces grivoiseries, que j'ai consacré, à l'âge des longs espoirs, mon premier et plus sérieux effort. ${ }^{77}$

Nous devons à Bédier d'en avoir défini le genre : «Les fabliaux sont des contes à rire en vers », écrivait-il dans un chapitre préliminaire, avant de préciser :

Le mot désigne toujours les contes, en tant qu'ils sont parvenus à la forme littéraire, rimée par un poète. Par là, ils s'opposent aux mots contes, œuvre, fable, matière, aventure, qui désignent le sujet brut du conte. Le fabliau est l'œuvre d'art pour laquelle la matière, l'aventure, etc., ont fourni les matériaux. ${ }^{78}$

Ainsi, en mettant en vers ses « joyeux petits contes » issus de la tradition orale, Régis Roy refaisait à sa façon le chemin des auteurs de fabliaux du moyen âge. Il partageait tout autant les qualités que les défauts de ces vers « destinés à la récitation publique », à peu près jamais au chant, et où «l'intention plaisante domine ».

En fin de parcours, Bédier s'interroge sur leur valeur esthétique : «Comme œuvres d'art, que valent les fabliaux ? ». Frappé par « l'absence de toute prétention littéraire », il constate « une poétique très rudimentaire » qu'il justifie ainsi :

S'amuser soi-même, amuser le passant, conter non pour faire valoir ses talents de poète, mais pour conter, tel est le but. Être bref, plaire vite, tel est le moyen. De là découlent toutes les particularités de la versification et du style des fabliaux, défauts et qualités. ${ }^{79}$

C'est pourquoi les trouvères choisissent par défaut le vers le plus facile, « l'octosyllabe rimant à rimes plates, [...] le mètre obligé de tout genre narratif. » Ils le manient « négligemment, sans

77. Joseph Bédier, Les Fabliaux, op. cit., p. 1.

78. Ibid., p. 36.

79. Ibid., p. 341-342. 
grand souci d'en faire valoir toutes les ressources $»^{80}$. Et Bédier de conclure :

Ainsi - et tel est bien le caractère essentiel des fabliaux - le poète ne songe qu'à dire vitement et gaiement son conte, sans prétention, ni recherche, ni vanité littéraire. De là ces défauts : négligence de la versification et du style, platitude, grossièreté. De là aussi des mérites, parfois charmants : élégante brièveté, vérité, naturel. ${ }^{81}$

Ces considérations éclairées du philologue et médiéviste français Joseph Bédier (1864-1938) nous ramènent vers Régis Roy (1864-1944), son exact contemporain. En l'excluant de son Anthologie de la poésie franco-ontarienne, vraisemblablement par distraction, René Dionne s'est montré par trop sévère pour la poésie fruste et les vers malhabiles du poète qui, bien conscient des limites de son art, réclamait l'indulgence du lecteur pour sa versification. En ce qui concerne le contenu et la portée de l'œuvre, il faut aller au-delà du style et reconnaître que cet amuseur, qui a « voulu faire œuvre divertissante, rien de plus », a participé à sa manière à la littérature régionaliste et qu'il est peut-être devenu le premier, voire l'unique, faiseur de fabliaux de la francophonie ontarienne. Ce faisant, il a modestement laissé aux spécialistes de la littérature orale, avant les grandes enquêtes ethnologiques, une riche collection de récits facétieux et donné une couleur originale aux premières attestations de contes populaires en Ontario français $^{82}$.

80. Ibid., p. 342.

81. Ibid., p. 347.

82. Remerciements : l'auteur adresse ses remerciements aux centres d'archives et à leur personnel qui ont mis à sa disposition les documents nécessaires à la rédaction de cette étude : d'abord, le Centre de recherche en civilisation canadienne-française de l'Université d'Ottawa, qui possède le fonds Régis-Roy, et $\mathrm{M}^{\mathrm{me}}$ Alice Cocunubova ; les Archives de folklore et d'ethnologie de l'Université Laval et M. James Lambert; le Musée canadien de l'histoire et M. Benoît Thériault ; enfin $\mathrm{M}^{\mathrm{me}}$ Josiane Bru, ethnologue responsable du chantier du Catalogue du conte populaire français, à l'Université de Toulouse II, qui a clarifié la désignation de quelques types absents du catalogue international. 